\title{
Intermittent Dieting: Theoretical Considerations for the Athlete
}

\author{
Jackson James Peos ${ }^{1, *} \mathbb{C}$, Layne Eiseman Norton ${ }^{2}$, Eric Russell Helms ${ }^{3}$, Andrew Jacob Galpin ${ }^{4}$ \\ and Paul Fournier ${ }^{1}$ \\ 1 The University of Western Australia (UWA), The School of Human Sciences, \\ Crawley Campus, WA 6009, USA; paul.fournier@uwa.edu.au \\ 2 Biolayne LLC, 19401 Jacobs River Run, Lutz, FL 33559, USA; layne@biolayne.com \\ 3 Auckland University of Technology, Sports Performance Institute New Zealand (SPRINZ) at AUT \\ Millennium, Auckland 0632, New Zealand; eric.helms@aut.ac.nz \\ 4 California State University, Biochemistry and Molecular Exercise Physiology Laboratory, \\ Centre for Sport Performance, Fullerton, CA 92831, USA; agalpin@fullerton.edu \\ * Correspondence: Jackson.peos@research.uwa.edu.au
}

Received: 11 December 2018; Accepted: 11 January 2019; Published: 16 January 2019

\begin{abstract}
Athletes utilise numerous strategies to reduce body weight or body fat prior to competition. The traditional approach requires continuous energy restriction (CER) for the entire weight loss phase (typically days to weeks). However, there is some suggestion that intermittent energy restriction (IER), which involves alternating periods of energy restriction with periods of greater energy intake (referred to as 'refeeds' or 'diet breaks') may result in superior weight loss outcomes than CER. This may be due to refeed periods causing transitory restoration of energy balance. Some studies indicate that intermittent periods of energy balance during energy restriction attenuate some of the adaptive responses that resist the continuation of weight and fat loss. While IER-like CER-is known to effectively reduce body fat in non-athletes, evidence for effectiveness of IER in athletic populations is lacking. This review provides theoretical considerations for successful body composition adjustment using IER, with discussion of how the limited existing evidence can be cautiously applied in athlete practice.
\end{abstract}

Keywords: intermittent energy restriction; diet-reducing; weight loss; caloric restriction; adaptive thermogenesis; composition—body; body weight maintenance

\section{Introduction}

Athletes often undertake periods of weight loss in an attempt to reduce fat mass (FM) while retaining fat free mass (FFM). Although absolute body weight loss may be the primary outcome of concern for individuals with overweight or obesity, it is important that weight loss strategies adopted by athletes minimise losses of FFM, so as not to compromise training and performance [1]. Altering body composition in such a manner may be advantageous to the athlete for various biomechanical, aesthetic, and locomotive reasons, thereby increasing the likelihood of competitive success in a target weight-class (e.g., combat sports, weight lifting), weight-sensitive sports (e.g., endurance events, ski jumping), or aesthetically judged sports (e.g., gymnastics and bodybuilding) [2]. Previous literature indicates that athletes commonly reduce their absolute body weight by $5-10 \%$ over a number of months prior to competition [3,4], although more dramatic weight losses of $\geq 7 \%$ of body weight within $24 \mathrm{~h}$ have also been observed [5,6]. To achieve the desired weight loss (and to maintain sports performance), typically combinations of nutritional and exercise interventions are recommended for athletes [1]. Within this population, the most common nutritional weight loss strategy implemented 
is continuous energy restriction (CER), for the duration of the weight loss phase [7,8]. Specifically, CER involves reducing energy intake every day relative to weight maintenance energy requirements [9]. Despite being currently accepted as an evidence-based dietary intervention for weight loss, CER is accompanied by a number of behavioral, metabolic, and endocrine responses that collectively threaten dietary adherence, oppose the continuation of fat loss, and predispose the individual to weight and fat regain upon completion of the period of energy restriction (ER) [10-15]. Furthermore, it is well documented in athletes that ER, in conjunction with high training loads, can lead to loss of FFM and decreased performance via reductions in muscle strength, reflexes, and glycogen stores and increased irritability [2,16-18]. Elite athletes competing at a reduced body mass in weight-class and aesthetic sports also experience increased risk of injuries and chronic fatigue, and impaired immune function, which can lead to more frequent episodes of illness [19]. In these sports, failure to reach target body weight or body composition in the days or weeks prior to contest through the use of ineffective or suboptimal dietary strategies may cause athletes to depend on more rapid weight loss techniques that could jeopardise performance and possibly be dangerous. Such techniques include acute "water weight" loss, a practice that often involves severe dehydration via restriction of fluid intake, and actively pursuing sweating through exercise (often in combination with "sweat suits") or the use of saunas and hot baths [20]. Dehydration is known to adversely affect athletic performance by reducing body water, electrolytes, and glycogen, which alter a number of physiological processes including metabolism, the regulation of body temperature, and cardiovascular function $[7,20]$. An additional challenge that athletes face when embarking on weight loss is the multitude of diet subtypes, the propagation of unfounded fad diets by the media, as well as conflicting nutritional research, all of which contribute to confusion regarding optimal manipulation of dietary variables for athlete weight reduction [21]. As such, there is an inherent need to review current and novel dietary strategies as a means of providing athletes with sound, evidence-based guidelines that facilitate the realisation of their body composition goals, without jeopardising health or performance.

Intermittent energy restriction (IER) is one nutritional strategy that has gained recent research attention [22-27] and which could potentially be of relevance to athletes wishing to reduce weight. IER involves alternating periods of ER with periods of greater energy intake (often referred to as 'refeed' periods or 'diet breaks'), within the weight loss phase. Of note, these ER and refeed periods have also been referred to as 'fast' and 'feed' phases in some previous publications [9]. The proposed goal of implementing refeeds during periods of ER is to briefly stimulate the release of some regulatory hormones that play a positive role on fat loss and satiety and increase metabolic rate [2]. While a conceivable metabolic and hormonal model to attenuate ER-induced adaptations through the use of an IER regime exists, recent literature has not been definitive. The concept of integrating periods of greater energy intake within a weight loss phase received research attention following work by Wing and Jeffery [28]. Investigators examined the effects of disturbing the momentum of weight loss in an attempt to induce dietary relapses during a 14-week weight loss program. Surprisingly, prescribed diet breaks did not lead to a backsliding of progress, with participants who adopted either a six-week diet break at Week 7 of the program or two-week diet breaks after Weeks 3, 6, and 9 of the program not demonstrating any less weight losses (at 0-5 months or 0-11 months) when compared to the control group who dieted continuously for the 14-week program. These findings caused some researchers to speculate that diet breaks or refeeds could encourage greater adherence to longer-term diets in individuals needing to lose significant amounts of body fat.

Previous research in the realm of IER has focused on populations with overweight or obesity [29]. However, the metabolic and training status of athletes is considerably different from that of people who are overweight or who are sedentary. Athletes are typically of a healthy body composition and undertake high levels of physical activity and consequently have high energy expenditures, as well as a low probability of experiencing metabolic diseases or preliminary states of diseases, which are often observed in populations that are overweight and inactive [30]. Therefore, it is possible that these factors could influence the response to IER. Additionally, it is conceivable that IER strategies could be more 
likely to benefit athletes (or lean people in general) as evidenced by leaner individuals demonstrating two- to three-fold greater protein losses [31], greater reductions in testosterone levels [32], and a higher proportion of weight loss from FFM during ER when compared to individuals with a BMI in the overweight or obese range [33]. To our knowledge, no published research is currently available on IER in athletes. Thus, the purpose of this review is to discuss the existing body of literature on IER, outline its potential as an alternative weight loss strategy for athletes, and set a platform for future investigation in athletes. This review will also utilise the available evidence to develop theoretical recommendations for athletes considering IER.

\section{Methods}

PubMed, MEDLINE, SPORTDiscus and CINAHL electronic databases were searched online. Each author was assigned a section of the manuscript to write specific to their area(s) of expertise. Authors performed searches for key words associated with their section(s) of the manuscript; intermittent energy restriction, continuous energy restriction, adaptive thermogenesis, adaptive responses to energy restriction, athlete weight loss, nutrition for body composition management, and nutrition for athletic performance were the selected topics. Long-term human studies with individuals of a healthy body weight comparing energy-matched IER and CER protocols were preferentially selected; however, given the paucity of such studies, studies using overweight individuals and studies using animal models were also selected. In addition, author names and reference lists were used for further search of the selected papers for related references. As this review is intended to serve as an evidence-based guide and the available data applicable to athletes is limited, a narrative review style was chosen.

\section{Adaptive Responses to Energy Restriction}

Before discussing the existing literature and potential benefits of IER, it is worthwhile to review the adaptive responses to energy restriction and how they affect body composition management.

\subsection{Energy Expenditure}

Resting energy expenditure (REE) typically constitutes $60-75 \%$ of total daily energy expenditure (TDEE) and is a function of body mass (particularly FFM, but also FM). Thus, weight loss causes a decline in REE via the loss of metabolically active tissue [2]. However, weight-loss-induced reductions in REE-which occur in both lean and obese individuals-exceed that which is predicted by decreases in FFM and FM alone [34,35]. Termed "adaptive thermogenesis" (AT), this metabolic alteration successively minimises the degree of energy deficit achieved by ER. AT can partially explain why weight loss plateaus are encountered despite continued intake of a diet with less energy than before weight loss, and likely contributes to the restoration of baseline body weight upon termination of an energy-restricted state [35-37]. AT has been studied frequently in overweight and obese populations, but not in athletes. One investigation reported that AT explained 50\% of the less-than-expected weight loss in obese women undergoing 14 weeks of $4200 \mathrm{~kJ}$ per day of ER [38]. A recent review highlighted the potential impact of AT by concluding that weight loss strategies are only transiently effective, as the majority of overweight or obese individuals were not able to achieve and maintain a 10\% reduction in absolute body weight over 12 months [12]. A meta-analysis also showed that in individuals who completed structured weight loss programs, over a third of the weight lost returned within the first year, with the majority of the rest gained back within 3-5 years [39]. Furthermore, in men with a healthy body weight, 24 weeks of ER ( $50 \%$ of energy requirements for weight maintenance) caused a $40 \%$ reduction in baseline energy expenditure. Weight loss accounted for $25 \%$ of this reduction and AT explained the remaining $15 \%$ [40].

Along with decreases in the resting component of TDEE, non-resting components, including exercise activity thermogenesis (EAT; energy expended for sports-like exercise and physical training) and non-exercise activity thermogenesis (NEAT; energy expended for activities that do not 
include sleeping, eating or sports-like exercise), also decline as reduced body mass demands less energy to complete certain activities, particularly when weight-bearing locomotion is involved [36,41-45]. One cross-sectional study found an $18 \%$ lower TDEE in people with obesity after a body weight loss of $23 \%$ when compared to individuals with the same body weight who had never dieted [42]. It was observed that the decrease in TDEE was largely due to reductions in non-resting components, accounting for $71 \%$ of the observed difference. Finally, the thermic effect of feeding (TEF) is lowered by consuming less energy overall during ER $[41,46]$. Reductions in TEF accounted for $18 \%$ of the fall in TDEE in people with obesity after weight loss [41]. Thus, the evidence suggests that ER and the associated weight loss cause a metabolic downshift in all components of TDEE (Figure 1), which could significantly influence long-term body weight management.

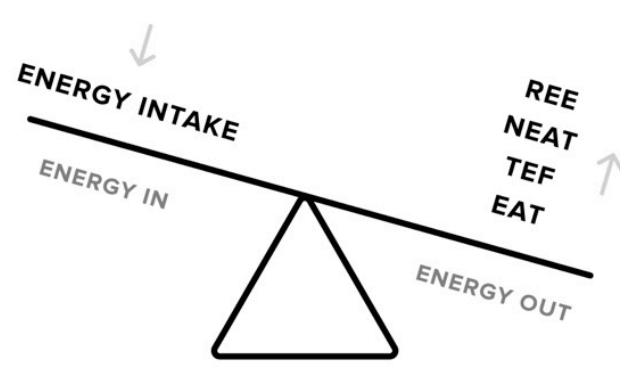

ENERGY DEFICIT

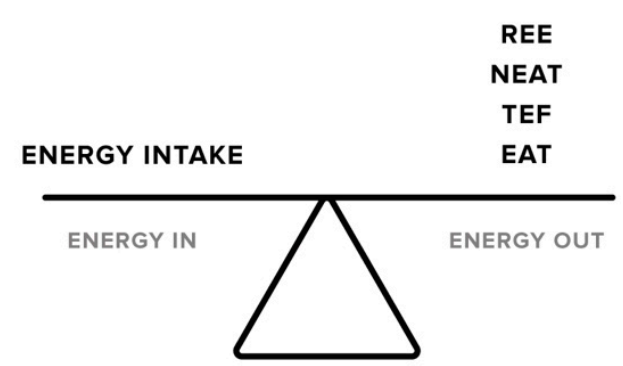

ENERGY BALANCE

\section{TIME IN ER}

Figure 1. Adaptive responses in energy expenditure during energy restriction (ER). Over the course of a weight loss phase, total daily energy expenditure will decrease as a consequence of declines in resting energy expenditure (REE), non-exercise (NEAT) and exercise activity thermogenesis (EAT), and the thermic effect of feeding (TEF). This results in a lessening of the energy deficit, which can cause plateaus in weight loss if energy intake matches the new level of energy output. Plateaus may only be overcome by a further reduction in energy intake or an increase in activity levels.

\subsection{Endocrine Responses}

A number of endocrine responses also accompany ER, including variations in thyroid, appetite-regulating, and steroid hormones that collectively influence energy expenditure, body composition, and satiety. Thyroid hormones play a prominent role in regulating energy expenditure whereby decreases in circulating or tissue levels of active forms reduce thermogenesis and REE [47]. Previous research suggests that up to $30 \%$ of REE is determined by thyroid hormones [48]. In terms of body composition, clinical observations in humans show that hypothyroidism can lead to a metabolic shift culminating in an increase in FM in combination with reduced FFM [49]. As reviewed previously, ER is associated with decreased thyroid hormone secretion $\left(\mathrm{T}_{3}\right.$ and $\left.\mathrm{T}_{4}\right)$ in lean healthy men and women [50]. A similar finding was also observed in a case study of a competitive athlete undergoing ER in preparation for a bodybuilding contest [51]. Additionally, in overweight or obese people, moderate ER has been shown to reduce overall hypothalamo-pituitary-thyroid axis function, causing a decline in circulating or tissue concentrations of active thyroid hormones, which is associated with a significant decrease in energy expenditure [52]. It is therefore possible that the inhibition of normal thyroid function in athletes undergoing ER may negatively influence the propensity for long-term weight/fat loss and increase the likelihood of loss of FFM and weight/fat regain.

Two well-known appetite-regulating hormones are leptin and ghrelin, which work in opposition of each other in this context. Leptin, a hormone largely synthesized in adipocytes, responds to 
energy availability such that low levels increase appetite while high concentrations yield the opposite response [53]. Leptin has also been shown to increase energy expenditure via effects on the hypothalamus [54]. Worthy of note, reductions in circulating leptin are frequently observed in ER studies of lean competitive athletes $[13,14,51,55]$. In men with a healthy body composition undergoing three weeks of ER ( $50 \%$ of energy requirements for weight maintenance), plasma leptin was reduced by $44 \%$ [56]. Another trial found that four days of ER ( $60 \mathrm{~kJ} / \mathrm{kg}$ of FFM per day) reduced circulating leptin by $53-56 \%$ in regularly exercising men [57]. The above evidence suggests leptin not only responds to overall adiposity but also short-term nutrient flux. Pharmacological administration of leptin can reverse some of the adaptive responses to ER-namely-reductions in REE, skeletal muscle work efficiency, and circulating thyroid hormone concentrations [58], yet further discussion of such interventions is beyond the scope of this paper.

In general opposition of leptin, the orexigenic hormone ghrelin reflects acute and chronic feeding states by increasing the drive to eat during periods of fasting and low energy intake [59]. As reviewed previously, since plasma ghrelin levels are dependent on recent energy intake, this hormone plays an important role in regulating hunger and meal initiation [60]. One study reported that plasma ghrelin-like immunoreactivity increased $31 \%$ after $12 \mathrm{~h}$ of fasting and was reduced by $22 \%$ immediately after a meal [59]. Leptin and ghrelin (absolute amounts and ratios) were significantly correlated with FM loss and changes in REE at both baseline and following 12 weeks of ER in obese women [61]. Therefore, lower leptin and higher ghrelin appear to oppose FM loss and may be viable biomarkers for predicting the magnitude of metabolic adaptations to ER, yet more research is needed to confirm. Decreased leptin and increased ghrelin in response to ER may oppose potential weight loss by significantly altering appetite (which could cause compensatory eating) or by reducing energy expenditure.

Insulin, which is an additional adiposity signalling hormone, responds to energy availability in a similar manner to leptin and plays an important role in preventing muscle protein degradation [62]. In humans-with either a healthy body weight or with obesity - significant reductions in fasting insulin concentrations have been reported during ER, potentially threatening maintenance of FFM [63-66]. Reduced insulin levels during ER are disproportionately low when compared to equal relative FM at a stable body weight, indicating a physiological shift acting to correct the state of energy depletion and favour weight regain [67]. Athletes recovering from strenuous exercise also require depleted fuel stores to be replenished, primarily through the insulin-mediated uptake of glucose in muscle [68]. Therefore, reduced insulin levels as a consequence of ER may impact the restoration of muscle glycogen stores. The importance of sufficient muscle glycogen content for the athlete is further discussed in Section 6.2.3.

Reduced activity of the reproductive and somatotropic axes is also a possibility during dynamic ER [49]. For instance, 8 weeks of ER (via heavy exercise and reduced energy intake) significantly reduced serum testosterone concentrations in healthy lean men [69]. Testosterone may be of particular interest to athletes due to its role in stimulating muscle protein anabolism leading to accumulation (and maintenance) of muscle mass [62]. However, several studies also confirmed a significant inverse correlation between reductions in FM and circulating testosterone levels [70]. Interestingly, some studies show that ER in men with a BMI in the overweight range either increases or has no impact on circulating free or total testosterone levels [71]. Therefore, reductions in testosterone during ER may only be of concern to individuals with a lean body composition. While reduced circulating concentrations of insulin-like growth factor-1 (IGF-1) has been observed in some cases of ER [72], it does not appear that growth hormone (GH) is significantly disrupted, as evidenced by no change in GH levels after 6 months of ER (25\% below weight maintenance requirements) [73].

In contrast to testosterone, serum increases in the glucocorticoid cortisol causes protein catabolism in healthy subjects [74]. Furthermore, a rodent trial showed glucocorticoid administration inhibited the potent energy dissipation and satiating effects of leptin, thereby suggesting glucocorticoids play a counterregulatory role on leptin action and contribute to leptin resistance [75]. 
Chronic hypercortisolism regularly occurs in highly trained athletes [76]. Additionally, salivary cortisol levels were elevated in male and female competitive gymnasts when compared to age-matched non-athletes [77]. While psychological stress likely played a role in the observed cortisol elevations, ER was a probable significant contributor. This is further evidenced by significant increases in serum cortisol in highly active lean men completing 8 weeks of ER resulting in weight loss [69]. As discussed in a narrative review, glucocorticoids such as cortisol also promote FM accretion [49]. Therefore, increases in cortisol output during ER may impede athlete weight loss efforts by promoting the conservation of FM and loss of FFM and by inhibiting the actions of leptin.

While not an exhaustive list of endocrine responses associated with ER, the above text illustrates a shift in the hormonal milieu in response to energy deprivation that collectively promotes reductions in energy expenditure and an increased drive to eat and threatens the retention of FFM (See Figure 2). For a more comprehensive explanation of the endocrine responses accompanying ER, we direct the reader to the following reviews $[49,52,78]$.

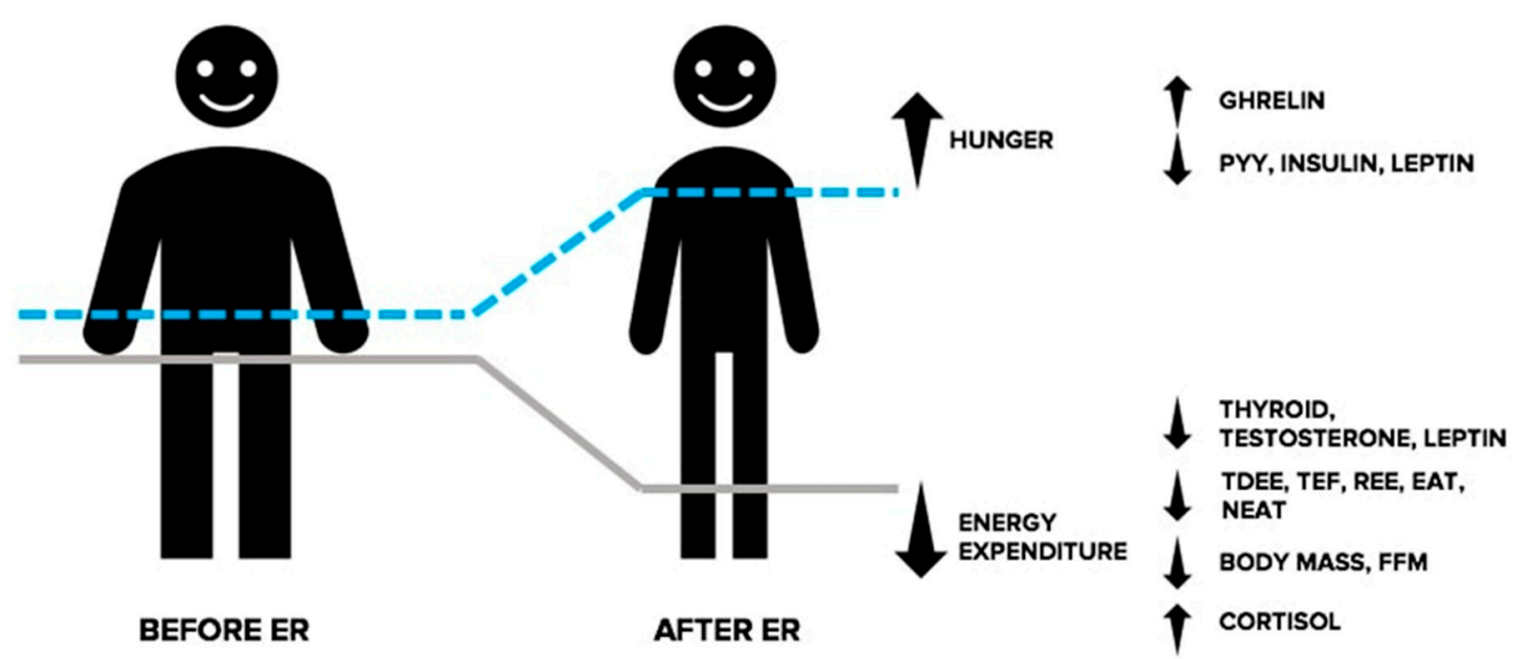

Figure 2. Adaptive responses in the endocrine system during energy restriction (ER). In response to ER, the resulting energy deficit and corresponding weight loss causes an increase in the drive to eat and reduced energy expenditure, collectively making the continuation of weight loss more challenging. Changes in circulating levels of orexigenic and anorexigenic hormones communicate a nutrient deprivation signal to the brain, causing stimulation of appetite, and a decrease in feelings of satiation. Furthermore, ER causes a shift in circulating levels of hormones involved with the regulation of thermogenesis and energy expenditure. Changes in these hormones indicate a physiological shift directed at correcting the state of energy deprivation and favouring weight regain. EAT: exercise activity thermogenesis; FFM: fat free mass; NEAT: non-exercise activity thermogenesis; PYY: peptide YY; REE: resting energy expenditure.

\subsection{Adaptations in Adipose Tissues}

The cellularity and metabolic characteristics of adipose tissues may contribute to the biological tendency for weight regain after weight loss. Reductions in body fat is accompanied by a decrease in the size of adipocytes as energy stores are mobilised [79,80], yet no discernible change in the number of adipocytes present in adipose tissue is observed [79-82]. Smaller adipocytes secrete less leptin for a given FM [12], therefore implying that the reduction in adipocyte size-as well as total FM-may contribute to the ER-induced decline in circulating levels of leptin. Furthermore, smaller adipocytes exhibit higher glucose uptake rates [83,84], a greater expression of genes favouring energy storage [85-87], and reduced lipolysis [12] compared to larger adipocytes. As reductions in adipocyte size has also been linked to remodelling of the extracellular matrix to accommodate this change in propensity for nutrient storage, it has been proposed that weight loss induces cellular stress that modifies the metabolic profile of adipocytes [88]. Conceivably, such a change would only 
be relieved via increased storage of lipid [89]. While the number of adipocytes remains relatively constant during adulthood [90], there are circumstances in which adipocyte number may increase. Previously published research in rodents demonstrates that adipocyte hyperplasia can occur in the early stages of weight regain after weight loss, resulting in a greater number of adipocytes in adipose tissue depots and thus a greater potential for storage of lipid [91]. Hyperplasia in adipose tissue could conceivably amplify the likelihood of rapid weight regain not only by increasing the size of the depot but also through the creation of small adipocytes with an enhanced capacity for uptake and storage of ingested nutrients (see Figure 3). It has been speculated that this phenomenon may partially explain situations in which pre-ER body weight is surpassed during the post-weight loss period $[12,79,80,86]$. Thus, the adaptations in adipose tissue-in combination with changes in energy expenditure and the endocrine milieu-can present a substantial challenge not only for successful weight loss but also for the maintenance of the reduced body weight.

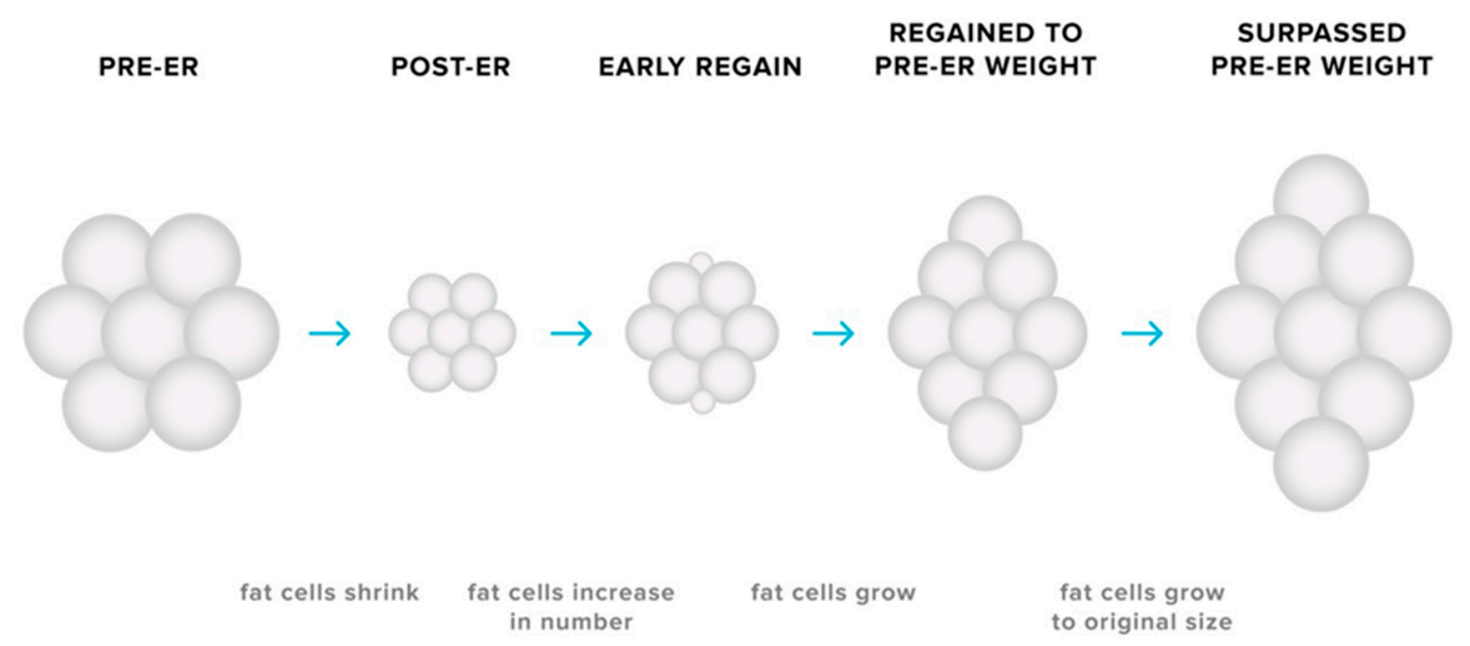

Figure 3. Adaptive responses in adipose tissues during energy restriction (ER). ER causes a decrease in the size of adipocytes, with no discernible change in adipocyte number in the adipose depot. Due to the modification of the metabolic profile of these smaller adipocytes, the potential for storage of triglyceride increases, subsequently making the maintenance of lost weight more challenging. The possibility of adipocyte hyperplasia early in the weight regain period may also increase the likelihood of weight-reduced individuals surpassing their pre-energy-restriction body weight.

\section{Intermittent Energy Restriction: An Overview of Effectiveness}

\subsection{Intermittent Fasting}

IER lacks clear definition, acting as an umbrella term encompassing a variety of dietary protocols that utilise different energy prescriptions during ER and refeeds as well as the length of these periods. The most common IER used in clinical trials is often referred to as 'intermittent fasting' (IF) [29]. IF has been defined previously as severe reduction of energy intake on 1-7 days, followed by a relatively greater energy intake on refeed days [29,92]. There may or may not be restrictions placed on the quantities and types of foods and beverages consumed during these refeed periods [27]. It is important to note that IF is one form of IER but has also been used to describe various other dietary interventions including time-restricted feeding approaches (such as the $8 \mathrm{~h}$ feeding window method) [93]. Alternate-day fasting is a sub-type of IF that involves partial or complete restriction of energy intake for $24 \mathrm{~h}$, followed by a refeed day where food is consumed ad libitum for $24 \mathrm{~h}$ [9,94-96]. Another sub-type of IF—known as the 5:2 (or 'fast') diet—alternates two days of severe ER with five refeed days per week $[27,97,98]$. The available evidence indicates that IF is not superior to CER as a weight loss strategy. In a recent review of 13 randomised comparisons of CER and IF in overweight individuals, all studies demonstrated comparable reductions in body weight where overall energy 
intake was matched [24]. In another recent review investigating the effectiveness of randomised controlled trials of IER compared with CER in overweight and obese adults, the authors concluded that IER involving ER on at least one day per week but no greater than seven days were equally effective as CER for short-term weight management [99]. Furthermore, the majority of trials reporting body composition outcomes have shown equal efficacy for reducing FM, visceral fat stores, and waist circumference when IF regimes were compared to CER in adults with overweight and obesity [24,92,97]. While the mass of literature has failed to establish a benefit to short-term IER regimes implementing ER on 1-7 days per week, greater weight loss efficiency (weight lost per unit of ER) was observed in mice with diet-induced obesity following an IER diet that involved 5-6 days of ER ( $82 \%$ of ad libitum chow-fed control) followed by ad libitum refeeding for 1-3 days, compared to CER ( $82 \%$ of ad libitum chow-fed control), after 12 weeks $(0.042 \pm 0.007$ versus $0.018 \pm 0.001 \mathrm{~g} / \mathrm{kJ}$, respectively) [27]. Despite the IER group eating significantly more than the CER group (91 versus $82 \%$ of control intake, respectively), the same magnitude of weight loss was achieved in both groups. Although these findings have not been replicated in published controlled human trials, potential benefits of IER have been recently demonstrated in preliminary research presented as a conference abstract $[100,101]$. An IER regime alternating five days of ER with twice-weekly refeeds was superior to CER in preserving REE $\left(-40 \mathrm{kcal} \cdot \mathrm{d}^{-1}, p=0.410\right.$ versus $\left.-78 \mathrm{kcal} \cdot \mathrm{d}^{-1}, p=0.017\right)$ and FFM $(-0.4 \mathrm{~kg}, p=0.460$ versus $-1.3 \mathrm{~kg}$, $p=0.001$ - —while causing equivalent FM loss ( 2.8 versus $2.3 \mathrm{~kg}$ ) -among resistance-trained athletes completing seven weeks of ER (energy intake $25 \%$ below weight maintenance energy requirements).

In one review, it was reported that alternate-day fasting caused less loss of FFM, with equivalent FM loss when compared to CER in adults with overweight and obesity [9]. This caused some to suggest that IF may be a more effective strategy than CER for mitigating FFM losses during ER. However, a recent randomised controlled trial involving 100 adults with overweight or obesity randomised to alternate day fasting or CER for 24 weeks showed similar improvements in the FFM-to-total-mass ratio between groups [25]. Additionally, a recent systematic review of 31 publications comparing IF with CER in humans of any age or BMI failed to demonstrate superior FFM retention using IF [27].

One proposed benefit of adopting an IER regime over CER is that refeed periods may provide a mental break from extended periods of ER, leading to improved long-term adherence to the dietary schedule. In one randomised controlled trial, participants were randomly allocated to a role-playing scenario that simulated either seven days of an IER model (six days of $1300 \mathrm{kcal} / \mathrm{d}$ followed by one day of $2700 \mathrm{kcal} / \mathrm{d}$ refeed) or CER (seven days of $1500 \mathrm{kcal} / \mathrm{d}$ ) [102]. While both simulated conditions were energetically matched $(10,500 \mathrm{kcal}$ per week), participants in the IER group demonstrated a higher-than-expected self-regulatory ability (they were expected to experience more positive affect during the diet phase) and generated more strategies to overcome dietary temptations than participants in the CER group. However, in a recent systematic review comparing short-term IER protocols ( $\leq 7$ days cumulative ER) with CER, dropout rates varied between 0 and $40 \%$ and were comparable between both groups, and to previous reports within other CER studies [24]. This suggests long-term adherence to short-term IER protocols may be similar to CER, presenting a viable-albeit not superior-alternative for individuals who find sustained daily ER difficult.

\subsection{IER Regimes Involving Longer Periods of ER}

In contrast to the above findings, some recent randomised controlled trials show better weight and fat loss with certain types of IER that incorporated longer-term periods of ER and refeeds (i.e., $\geq 7$ days of cumulative ER alternated with a lesser degree of prescribed dietary restriction, or no prescribed dietary restriction), when compared to CER. One possible reason for the apparently greater weight and fat loss, is that these protocols may mitigate some of the adaptive responses to ER that oppose ongoing weight and fat reduction. A six-week diet involving CER ( $45 \%$ of weight maintenance energy requirements) was compared with a six-week diet involving IER that cycled 11 days of ER (55\% of weight maintenance energy requirements) with 3 days of ad libitum feeding in 74 women with obesity [98]. There was significantly greater weight loss at four weeks after completion of the 
diet in women in the IER than in the CER group $(5.8 \pm 1.2$ versus $3.4 \pm 1.4 \%$ of initial body weight, respectively). Moreover, REE was maintained at higher levels in the IER than in the CER group. Perhaps the most convincing evidence for adopting a long-form IER protocol (over CER) can be found in findings from the recent "MATADOR" study. In this randomised controlled trial, 16 weeks of CER (67\% of weight maintenance energy requirements) was compared with 16 weeks of ER applied intermittently as eight two-week blocks of ER (67\% of weight maintenance energy requirements) alternating with seven two-week blocks of EB (where energy intake is matched to energy requirements for weight maintenance) in 51 men with obesity [22]. Significantly greater weight loss (14.1 \pm 5.6 versus $9.1 \pm 2.9 \mathrm{~kg}, p<0.001)$ and FM loss $(12.3 \pm 4.8$ versus $8.0 \pm 4.2 \mathrm{~kg}, p<0.01)$, as well as less compensatory reduction in REE $\left(-360 \pm 500\right.$ versus $\left.-750 \pm 500 \mathrm{~kJ} \cdot \mathrm{d}^{-1}, p<0.05\right)$ and better maintenance of lost weight at a six-month follow-up $(-11.1 \pm 7.4$ versus $-3.0 \pm 4.4 \mathrm{~kg}, p=0.001)$, were observed in the IER compared to the CER group. Furthermore, FFM loss was the same in both groups despite greater FM loss in the IER group. In a third randomised controlled trial, equal weight loss was achieved among overweight women following either 8 weeks of CER (5500 kJ ER per day) or 8 weeks of IER administered as one week of ER (5500 kJ ER per day) alternating with one week of the participants' habitual diet (no prescribed ER) $(-3.2 \pm 2.1 \mathrm{~kg}$ CER, $-2.0 \pm 1.9 \mathrm{~kg}$ IER) [103]. While findings could be interpreted as a lack of superiority to this long-form IER protocol due to equivalent weight loss, it is important to consider that the IER group spent less time in ER compared to the CER group (4 weeks in IER versus 8 weeks in CER), resulting in greater weight loss efficiency.

Findings from these trials indicate that these forms of IER attenuated the adaptive response to $E R$, at least with respect to reductions in REE. Strategies—such as intermittent refeed periods-that potentially attenuate reductions in energy expenditure are important, as literature demonstrates people who regained $>30 \%$ of weight lost after ER showed reduced energy expenditures when compared to those who remained weight-stable (within $< \pm 20 \%$ of weight change) [104]. Furthermore, the estimated risk of gaining $>7.5 \mathrm{~kg}$ in body weight over a two-year longitudinal study increased fourfold in people with low $24 \mathrm{~h}$ energy expenditures compared to people with high $24 \mathrm{~h}$ energy expenditures [105]. Adjusted REE was also found to predict the gain in body weight over a four-year follow-up period [105].

Although the above long-form IER protocols display some inherent benefits over CER, in a recent systematic review and meta-analysis-which did not include the above studies-five randomised controlled trials of IER incorporating $\geq 7$ days of cumulative ER were compared with CER for the treatment of overweight and obesity in adults [23]. Meta-analysis demonstrated no significant difference in weight loss at post-intervention (weighted mean difference: -1.36 [ $-3.23,0.51], p=0.15$ ) or at follow-up (weighted mean difference: $-0.82[-3.76,2.11], p=0.58$ ). To help clarify the disparity in the literature, Peos and colleagues will be the first to examine a long-form IER regime alternating three-week blocks of ER with one-week blocks of EB in resistance-trained athletes [106] (See Figure 4).

While attenuation of the decline in REE has been observed with some IER protocols when compared to CER, it remains to be seen whether these dietary regimes also result in minimisation of some of the other adaptive responses associated with ER. Under some circumstances, a number of the adverse metabolic and hormonal outcomes associated with weight loss have been reported to be quickly reversed upon restoration of EB, namely normalisation of fasting and postprandial energy expenditure, and circulating levels of leptin and thyroid [107-113]. In one trial among postmenopausal women, following 10 days of ER (3350 kJ per day), reductions in body composition-adjusted REE and circulating levels of thyroid hormones were returned to baseline after 10 days in EB [114]. Furthermore, in overweight women following a very-low-energy diet for 28 days, suppressed serum thyroid parameters returned to baseline concentrations following one week of increased energy intake (4200 kJ) [115]. Thus—as previously discussed in a narrative review-a number of the undesirable consequences associated with weight loss are related to the ER itself, not to the weight loss per se [12]. 


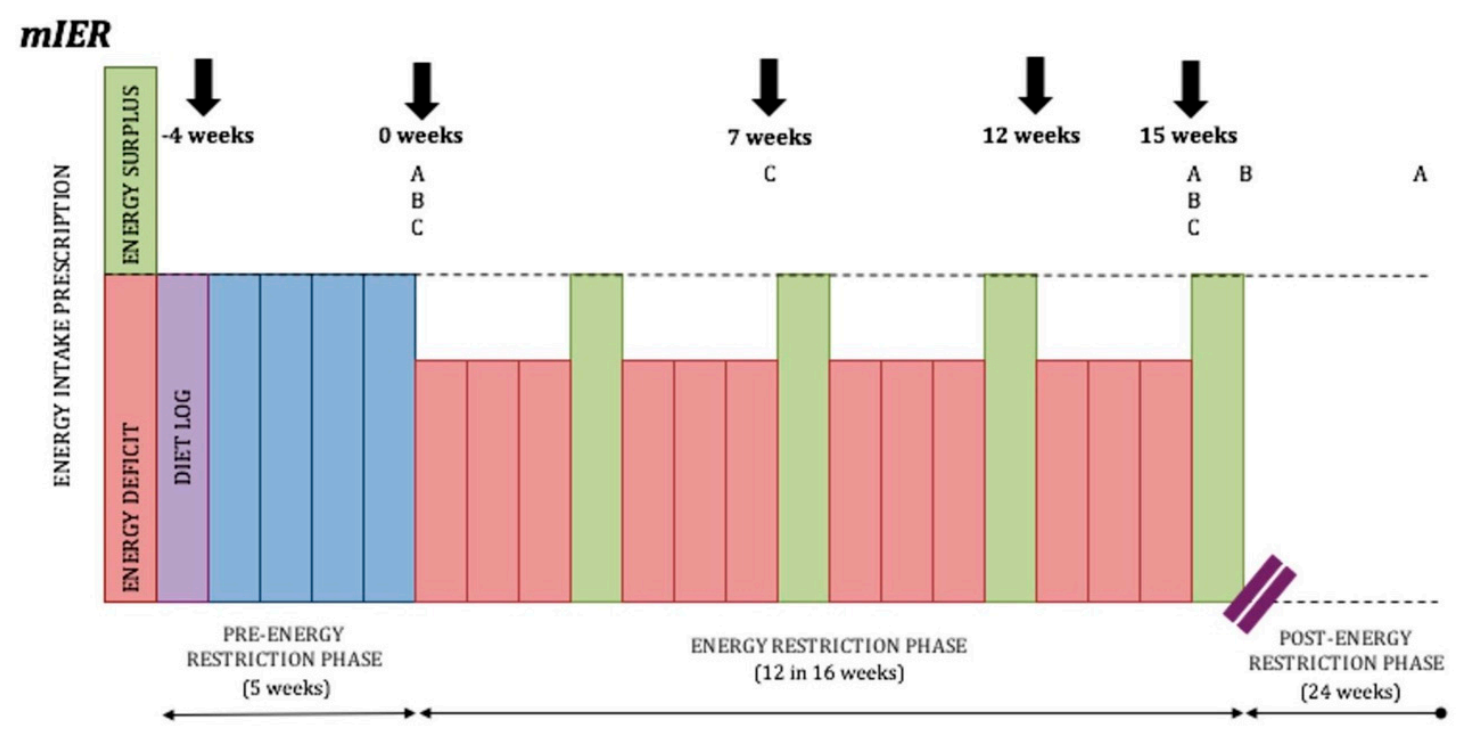

Figure 4. Long-form IER protocol designed by Peos and colleagues. (A) Fat mass, fat free mass, and body weight measured at 0 weeks, 15 weeks, and at 6 months in the moderate intermittent energy restriction group (mIER); (B) muscle performance, resting energy expenditure, a drive to eat, and levels of appetite-regulating hormones measured at 0 weeks, 15 weeks, and 16 weeks; (C) mood states, diet acceptability, physical activity, and sleep quality measured at 0 weeks, 7 weeks, and 15 weeks.

There is evidence that levels of leptin [116] and thyroid hormones [117] can be temporarily increased following short-term overfeeding. In one trial, the subsequent elevation in leptin following overfeeding resulted in a 7\% increase in TDEE [118]. These findings have caused speculation among some athletes and coaches that refeed periods may stimulate an increase in circulating levels of these regulatory hormones leading to temporarily inflated metabolic output and reversal of adaptive mechanisms associated with ER. However, it remains to be seen whether the same stimulatory effect on leptin release and thyroid activity can be achieved with controlled refeeding during IER where participants temporarily increase energy intake to levels for EB, as opposed to overfeeding. If this was indeed the case, the stimulatory effects on energy expenditure and fat loss via increased thyroid and leptin output, in conjunction with leptin's influence on satiety, would likely decrease the drive to eat-enabling better dietary adherence-and facilitate greater weight loss efficiency. Recently, in a series of in-depth interviews with seven experienced male competitive bodybuilders, participants frequently reported the implementation of refeeds during contest preparation [119]. According to the participants, the purpose of refeeds was to "prevent downgrades in energy expenditure, replenish intramuscular glycogen stores, and provide mental refreshment." Some participants claimed better fat loss, muscle retention, and less reduction in energy expenditure when using refeeds during pre-contest weight loss, compared to weight loss without refeeds. However, it is unknown how the participants were able to perceive such differences.

\subsection{Limitations of the Existing Literature}

The current body of research suggests IER may be offered as a viable, albeit not superior, alternative to CER for management of body composition. However, several limitations persist. Firstly, many IER protocols are collectively grouped together in systematic reviews and meta-analyses despite substantial heterogeneity between dietary regimes, suggesting a notion that all IER models are similar in design and efficacy. Therefore, it is difficult to determine whether equivalent findings in many of these reviews were due to certain IER manipulations or IER itself. An additional limitation is the inclusion of IER regimes that still prescribed an energy deficit (albeit minimal) during refeed periods, or trials where participants were instructed to eat ad libitum on occasion, but ate far less than expected and thus did not attain EB. As previously mentioned, the attenuation of adverse responses to ER 
using long-form IER protocols appears to be dependent on the restoration of true EB $[107,108]$. Hence, comparable findings between CER and IER protocols that did not establish EB during refeed periods should be expected. Another concern for a number of trials included in the reviews is whether there was sufficient statistical power to detect sensitive differences in the loss of FM and FFM between diet arms.

\section{Practical Considerations: Intermittent Energy Restriction for Athletes}

As the majority of above-mentioned research is limited to overweight and obese populations, it is unknown whether athletes respond to IER in a similar fashion. Athletes commonly need to reduce weight for sport purposes, so the following will take use of the available literature to discuss some of the practical strategies athletes considering IER could use to engage in the most evidence-based weight loss approach. We will discuss implications of incorporating resistance exercise during IER and considerations for the size of the relative energy deficit, the duration of weight loss, and dietary composition. While randomised controlled trials exploring IER in active individuals of a healthy body composition are scarce, there is evidence of athletes already adopting this dietary strategy $[2,120,121]$. However, there is a lack of consensus among coaches and dieticians on how to successfully employ IER in athletes, with many IER protocols being based on speculation or anecdotal evidence.

\subsection{Resistance Exercise}

As FFM is a critical predictor of REE, minimising losses may enhance long-term weight loss success and prevent rapid weight regain by abating metabolic downturn. A commonly cited 'rule' suggests that $\sim 25 \%$ of weight loss will be FFM, with the remaining $75 \%$ FM [33]. Yet this is inappropriate, often underestimating the proportion of FFM lost during weight loss [10]. Previous findings report $\sim 40 \%$ of weight loss was accounted for by FFM in normal-weight active army rangers after losing $10 \mathrm{~kg}$ over 8 weeks [122]. In lightweight rowers, $6 \%$ body weight loss over 8 weeks resulted in 50\% attributed to FFM loss [123]. However, evidence suggests that resistance exercise may preserve FFM during weight loss in both men and women with either healthy weight or obesity, completing moderate ( $2000 \mathrm{~kJ}$ ER per day) or severe ( 3200 kJ very-low-calorie-diet) ER [120,124-126]. Thus, resistance exercise appears to be a worthwhile strategy for athletes to implement during IER. In keeping with this stand, elite athletes undergoing moderate ER (0.7-1.4\% absolute body weight loss per week) who concomitantly undertook four intense resistance exercise sessions per week were shown to retain their FFM [127]. Additionally, moderate weight loss in female athletes performing weekly aerobic and resistance exercise did not cause reduction in their FFM after four weeks, despite the participants achieving absolute body weight losses of $0.5 \mathrm{~kg}$ per week [128]. However, preserving FFM during ER appears to be extremely difficult for very lean male and female athletes, regardless of intense resistance exercise [129-131]. In elite lean male bodybuilders (9.1\% body fat prior to beginning ER), nine weeks of ER reduced percentage body fat to $5.0 \%$ but was accompanied by a significant loss of FFM from 90.60 to $88.14 \mathrm{~kg}$ [130]. Furthermore, in five lean athletic females and five female competitive bodybuilders, 12 weeks of ER in preparation for a contest resulted in a $5.80 \mathrm{~kg}$ loss of body weight, with $23.8 \%$ of this weight loss accounted for by reductions in FFM [131]. With the evidence considered, it appears that adiposity has a protective effect against loss of FFM during ER and should therefore be of greater concern for lean individuals considering weight loss interventions. As a final note concerning resistance exercise prescription-IER may have particular application to training athletes by allowing the coordination of refeed periods with key performance outcome-focused training sessions/blocks. Such a tactic would provide optimal nutritional support for these sessions while potentially negating the unwanted performance consequences of sustained daily ER.

\subsection{Avoiding Severe Energy Restriction}

A limitation of some IER protocols is that the level of restriction is severe, particularly with IF. In a recent review of weight loss composition [33] and FFM-FM interrelationships in humans [132], it was 
recognised that greater degrees of ER are often accompanied by larger relative FFM losses. In addition to poorer FFM retention, severe ER has previously been associated with less weight loss efficiency, greater metabolic fluctuation, and excessive hyperphagia when compared to more moderate ER in athletes, and in overweight individuals [127,133-136]. Furthermore, adhering to intermittent severe reductions in energy intake may prove difficult for some people, as evidenced in a systematic review which identified an increase in appetite and irritability in individuals assigned to IF [29]. In most instances, it would seem wise for athletes to avoid severe ER due to potential adverse health and performance outcomes. As recognised in previous reviews and a recent consensus statement from the International Olympic Committee $[1,2,18,127]$, these outcomes include reductions in muscle strength, glycogen stores and reflexes, and increased risk of injury due to fatigue. Published scientific trials also demonstrate that gradual weight loss rates are superior to aggressive ones for athletes. In female athletes, $0.5 \mathrm{~kg}$ of weight loss per week was preferable over $1 \mathrm{~kg}$ per week after 4 weeks of ER, with a $30 \%$ greater reduction in testosterone levels and a 5\% decrease in bench press strength in the faster weight loss group [128]. Additionally, comparing weekly weight loss rates of $0.7 \%$ to $1.4 \%$ (of absolute body weight) in elite athletes displayed greater fat loss (31\% $\pm 3 \%$ versus $21 \pm 4 \%$ ) and an increase in FFM in the slower group versus no change in the faster group $(2.1 \% \pm 0.4 \%$ versus $-0.2 \% \pm 0.7 \%$, respectively) [127]. As previously discussed in a recent review, it seems wise to tailor energy deficits during ER to cause moderate weight loss of $0.5-1 \%$ of body weight per week, to minimise FFM loss and performance decrement [137]. With the evidence considered, an athlete considering IER should be encouraged to adopt moderate, as opposed to severe, ER. As a practical example of moderate ER, this could involve a maximum of $35 \%$ restriction of energy intake relative to weight maintenance energy requirements [138].

\subsection{Duration of Weight Loss and Refeeds}

Recent findings demonstrated that a diet involving IER which cycled two weeks of moderate ER with two weeks in EB was superior to moderate CER in men with obesity, in terms of fat loss and maintenance of REE after 12 weeks of ER [22]. However, a caveat of this IER model is the considerably greater time required within the intervention in the IER group ( 30 weeks versus 16 weeks), despite both groups completing equal time in ER. Typically, athletes will reduce body weight for competition over 8-16 weeks [1], so the above IER protocol may seem unattractive to athletes by significantly extending the duration of the weight loss phase. A worthy question is, could the same increase in fat loss efficiency, and the attenuation of REE reduction be achieved if blocks of EB were less frequent and of less duration (hence reducing total intervention duration)? Such a result may increase the appeal of IER to the athletic community. Peos and colleagues aim to answer this question by investigating a three-week-ER-one-week-EB model [106].

As an additional consideration, it might be important that periods of EB implemented during IER are not too short, as available research on overweight adults suggests that the reversal of some of the compensatory responses to ER may require at least 7-14 days in EB $[107,108,139,140]$. In one trial, it was observed that reductions in REE consequent to ER in obese women could persist $\geq 8$ weeks post-weight loss despite an increase in energy intake and weight stabilisation [141]. The persistence of some of the adaptive responses to ER beyond the weight loss period has also been observed in active people with a healthy body composition. Twenty-seven female fitness competitors completed four months of ER and successively reduced their FM by 35-50\% (DEXA, bioimpedance, skinfolds, $p<0.001$ ) [142]. After a 3-4-month recovery period comprising an increase in energy intake to pre-diet values and concomitant reduction in aerobic exercise, testosterone and thyroid hormones $\left(\mathrm{T}_{3}\right)$ had still not returned to baseline.

These findings suggest that ER awakens the body's homeostatic defence system in a manner that is persistent, and not easily counteracted. Interestingly, short-term $24-48 \mathrm{~h}$ refeed periods are commonly implemented in athlete weight loss practice $[2,100,101,119,143]$. While available literature does not indicate that the complete resolution of the adaptive responses to ER is likely with such short-term 
bouts of refeeding, it is unknown whether this strategy could still provide partial normalisation to pre-diet values-and if so-what implications this may have on weight reduction efforts. Although the effects of short-term refeeding (24-48 h) has not been examined extensively in trials involving athletes, aggressive $24 \mathrm{~h}$ refeeding has been investigated in energy-restricted women with suppressed luteinizing hormone pulse frequency $(-57 \%$ to $8.1+/-1.5$ pulses per $24 \mathrm{~h})$ and thyroid hormone levels $\left(\mathrm{T}_{3}-22 \% p<0.005\right)$ [144]. Following one day of refeeding ( $375 \mathrm{~kJ}$ per $\mathrm{kg}$ of FFM), the acute increase in energy intake was not sufficient to restore thyroid profiles or luteinizing hormone pulsatility. However, in a second randomised controlled trial, $48 \mathrm{~h}$ of refeeding after a three-day fast restored luteinizing hormone pulsatility in a group of women within $15 \%$ of their ideal body weight [145]. Furthermore, better maintenance of REE during weight loss was observed using weekly $48 \mathrm{~h}$ refeeds versus CER in a cohort of resistance trained athletes $[100,101]$. Therefore, the evidence suggests that not just the magnitude of energy intake but also the time spent within EB is important in achieving the reversal of some of the adaptive responses associated with ER.

\section{Dietary Considerations: Intermittent Energy Restriction for Athletes}

The effect of varying macronutrient ratios within a given energy quota has received considerable research attention. ER induces weight loss by imposing an energy deficit, regardless of whether a particular diet is geared toward manipulation of a certain macronutrient (e.g., low fat, low carbohydrate, and high protein) $[21,146]$. However, approaching weight loss in a solely "energy in/energy out" manner fails to consider the effects dietary composition may have on additional outcomes including the composition of weight lost, satiety, the thermic effect of feeding, and ease of compliance. As for micronutrition, athletes will typically not require vitamin and mineral supplementation while consuming adequate energy to maintain body weight from a variety of food sources. However, during ER (particularly severe ER), or if the diet consists largely of foods low in micronutrient density it may be necessary to consume a vitamin/mineral supplement to reach daily micronutrient requirements. For further reading on this topic, we direct the reader to [147].

\subsection{Protein Intake}

Protein increases satiety and has a higher thermic effect of feeding compared to carbohydrate or fat, so higher protein ( $>25 \%$ of energy intake) diets may be beneficial to weight management by increasing energy expenditure and improving compliance [148-151]. As the success of a weight loss diet is ultimately determined by adherence to a set intake, ease of compliance should be an important consideration. Reduced energy intake was reported in healthy individuals fed an ad libitum high-protein diet ( $30 \%$ of energy intake) versus an isocaloric lower protein diet ( $15 \%$ of energy intake), demonstrating the satiating effects of dietary protein [152]. High protein diets also exert stimulatory effects on muscle anabolism, reducing FFM losses during ER [152-154]. In resistance-trained athletes, high protein intake $(\sim 2.3 \mathrm{~g} / \mathrm{kg})$ during weight loss led to retention of FFM, but lower protein intake $(\sim 1 \mathrm{~g} / \mathrm{kg})$ during weight loss led to loss of FFM [30]. Collective literature suggests that a protein intake of $1.2-2.2 \mathrm{~g} / \mathrm{kg}$ of absolute body mass is sufficient for athletes in positive EB [153-156]. However, a recent systematic review indicates a range of protein intake from $2.3-3.1 \mathrm{~g} / \mathrm{kg}$ of FFM may be more appropriate for athletes undergoing ER with concurrent resistance exercise [137]. High protein intake is therefore a recommended dietary strategy for athletes to implement during IER, associated with increased satiety, a high thermic effect of feeding, and attenuated FFM losses. Protein supplements, protein dosing in close proximity to resistance exercise, and other dietary supplements including creatine and HMB may aid in FFM retention during ER, but a review of these topics is beyond the scope of this article. For further reading on these topics, we direct the reader to [137]. 


\subsection{Carbohydrate Intake}

\subsubsection{The Carbohydrate-Insulin Fat Loss Hypothesis}

It has been suggested that a low carbohydrate diet may facilitate weight loss by providing a metabolic advantage [157]. This is based largely on the "carbohydrate-insulin" hypothesis that a lower carbohydrate intake will expedite lipolysis via diminished insulin activity. On the contrary, a recent meta-analysis concluded that a low carbohydrate diet was no more effective than a low fat diet in terms of weight loss [158]. Furthermore, a subtype of the low carbohydrate diet, the ketogenic diet, elevates levels of circulating ketones causing a physiological state known as nutritional ketosis. By restricting carbohydrates to less than $10 \%$ of total energy intake, ketosis has been proposed to cause a weight loss advantage by reducing insulin-mediated inhibition of lipolysis and enhancing fat oxidation through the utilization of ketone bodies [20]. However, a recent review has since determined that, when diet interventions match protein and energy intake between ketogenic and non-ketogenic conditions, no fat loss advantage to a ketogenic approach is observed [159]. Collectively, this suggests that the effectiveness of a weight loss diet is not dependent on ratios of carbohydrate and fat intake but instead the absolute amount of energy and protein ingested.

\subsubsection{Performance Considerations}

Regardless of an athlete electing to take an intermittent or continuous approach to ER, a key concern is whether the composition of the diet is sufficient to support training and performance demands. Carbohydrate provides a versatile substrate for muscular work, supporting physical activity over a wide range of intensities due to its use by both anaerobic and aerobic pathways [160]. Higher carbohydrate intake may be preferable over higher intake of dietary fat by improving exercise efficiency, due to the greater yield of ATP per volume of oxygen deliverable to the mitochondria [161,162]. Additionally, evidence suggests that inadequate carbohydrate intake can impair both strength [163] and endurance performance [164]. Furthermore, the depletion of glycogen and blood glucose stores via low carbohydrate availability is associated with muscular fatigue, reduced work rate, and increased perception of effort [160]. Guidelines for carbohydrate intake recommend a range of 3-5 g/ $\mathrm{kg}$ of absolute body weight per day for athletes competing in low intensity, skill-based sports and 6-10 g/ kg/day for endurance sport athletes (1-3 h/day moderate to high intensity exercise) [165]. Higher carbohydrate intakes may also be preferable for bodybuilders, as a recent cross-sectional study recognised that, out of 51 competitors, those placing in the top five had greater carbohydrate intakes at the start of contest preparation ( 5.1 versus $3.7 \mathrm{~g} / \mathrm{kg}$ of absolute body weight) than competitors who did not [143]. During ER, it may not be possible to reach the above carbohydrate recommendations with simultaneous high protein intake and low energy intake. Nonetheless, where protein targets are reached, it seems practicable for athletes undergoing IER to allocate a majority of their remaining energy allowance to carbohydrate.

\subsubsection{Refeeds}

As discussed in a previous review, increased carbohydrate ingestion increases intramuscular glycogen storage, which may improve resistance exercise performance and recovery time, and allow an athlete to tolerate higher training volumes [166]. In a recent study, CrossFit athletes who increased their carbohydrate intake to $6-8 \mathrm{~g} / \mathrm{kg} /$ day for three consecutive days demonstrated greater improvements in repetitions completed during a 12 min test compared to athletes with a carbohydrate intake $<6 \mathrm{~g} / \mathrm{kg} /$ day [167].

Leptin release also appears to be particularly responsive to increased carbohydrate intake $[118,168]$. An influx of carbohydrate on refeed days could also lead to a more pronounced muscle protein synthesis response if IER is applied in concert with resistance exercise through the insulin-mediated activation of the Akt/mTORC1 pathway [169]. Positive muscle protein balance could be further enhanced by insulin-mediated reductions in cortisol and muscle protein breakdown [170]. 
Although yet to be confirmed in the context of IER, it is possible that a more pronounced anabolic (or diminished catabolic) response to resistance exercise provided via carbohydrate refeeding could reduce FFM losses during ER. The current scientific literature suggests that preference should be given to increasing carbohydrate intake during refeed periods as opposed to increasing intake of protein or dietary fat.

As an additional theoretical rationale for carbohydrate-dominant refeeds, ER leads to an increase in whole body sensitivity to insulin and a concomitant alteration in both carbohydrate and lipid metabolism [171,172]. Specifically, ER has been demonstrated to cause suppression of postprandial and $24 \mathrm{~h}$ fat oxidation [173-175], with carbohydrate becoming the preferential fuel source in peripheral tissues for energy requirements $[79,91,176]$. Such a response increases the potential for dietary fat to be diverted toward adipose tissue as opposed to oxidative pathways. Preferential use of carbohydrate for energy needs while trafficking fat toward adipose is the most energetically efficient means of restoring depleted energy reserves, with the energy cost of depositing dietary fat $(<2 \%$ of nutrient excess) being far less than the cost of depositing excess glucose ( $25 \%$ of nutrient excess) via de novo lipogenesis [177]. Thus, low dietary fat/high carbohydrate refeeds may be superior to high fat refeeds in individuals undergoing ER with perturbed fuel metabolism, which favours the trafficking of a substantial amount of dietary fat toward lipid pools, in a system primed for very energetically efficient weight and fat regain.

\subsection{Fat Intake}

Sufficient dietary fat is an essential component of a balanced diet, facilitating the uptake of fat-soluble vitamins, supporting cell membrane structure, as well as providing energy [160]. Insufficient dietary fat intake may also lead to a decline in testosterone levels [178], potentially threatening the maintenance of FFM. However-as reviewed previously-research suggests that a high fat diet may impair an athlete's ability to perform optimally during training and competitive efforts [179]. Studies using CER implemented with regular resistance exercise also demonstrate that higher-fat, lower-carbohydrate approaches $[151,180]$ may be less effective than lower-fat, higher-carbohydrate approaches for preserving FFM $[30,127]$. Thus, if resistance exercise is implemented during IER then a higher carbohydrate intake in place of dietary fat may facilitate greater FFM preservation, likely through the maintenance of training volumes. Typically, dietary recommendations for athletes during ER are to maintain an adequate but lower end dietary fat intake (15-20\% of energy intake) while emphasizing carbohydrate intake to fuel performance $[1,137,160,165]$. Of note, the above-listed nutritional considerations for the athlete are not exhaustive. For a more comprehensive examination of the implications of diets and body composition, readers should refer to the recently published position stand from the International Society of Sports Nutrition [21].

\section{Summary}

Athletes are known to have high levels of physical activity energy expenditure. Despite this, dietary interventions may be required to reduce body weight or body fat for maximising chances of competitive success. Ideally, this should be achieved via safe and effective nutritional strategies that minimise loss of lean tissues, health, and performance and reduce reliance on extreme or rapid weight loss practices. While yet to be demonstrated in athlete trials, IER is an effective means of reducing energy intake, body weight, and body fat. However, more importantly, some research suggests that IER may yield benefits over traditional CER by reducing some of the compensatory responses to ER, thereby increasing fat loss efficiency and reducing the likelihood of rapid weight regain. Furthermore-though yet to be confirmed-it is feasible that the implementation of high-carbohydrate refeeds may facilitate the maintenance of higher training volumes and augment the anabolic response following resistance training during these periods, potentially reducing FFM losses during ER. It is also possible that additional nutritional support provided by the coordination of refeed periods with a 
high volume or outcome-focused training phases/sessions may lead to improved performance. Finally, IER may be more acceptable to athletes as ER is only required during certain periods of the weight loss phase rather than the entire duration. While some advantages to an IER approach have been observed in non-athlete populations, we cannot yet confidently extrapolate these findings to athletes. Additionally, a number of the above-proposed benefits are still speculative.

Given the deficiency of research on IER in the context of athletes, optimal nonlinear dietary strategies are yet unknown. As such, there is a significant research opportunity for investigators interested in exploring various patterns of restriction (e.g., duration and level of energy intake for ER and refeed periods, ratios of ER to refeeds) and the manipulation of other dietary variables (e.g., macronutrition) to clarify how IER should be implemented in athlete populations as well as in the general public (if at all). Future investigation in the realm of IER should explore whether the recruitment of active individuals with healthy body composition, and the implementation of resistance exercise and optimised macronutrient intake would influence results achieved with IER. Nonetheless, we have provided a number of practical recommendations for an athlete wishing to implement IER in pursuit of his/her body weight or composition goals.

- Avoid severe IER and/or rapid weight loss. Severe ER may cause greater FFM losses than moderate ER, particularly in lean athletes. Severe ER may also adversely affect health and performance outcomes including reduced muscle strength, glycogen stores, and reflexes and increase the risk of injury due to fatigue and loss of FFM. It would be practicable for an athlete to adopt a moderate level of ER that encourages absolute body weight losses of $0.5-1 \%$ per week. Alternatively, an athlete may elect to reduce energy intake by a maximum of $35 \%$ relative to energy requirements for weight maintenance.

- Resistance exercise. Athletes implementing IER should be encouraged to partake in regimented resistance exercise as a means to attenuate FFM losses. Greater retention of FFM will likely minimise performance decrement during ER and may lead to greater fat loss efficiency by mitigating compensatory reductions in REE.

- Duration and ratios of ER and refeeds. With the limited human research available, a conservative practical recommendation is to alternate two weeks of moderate ER with two weeks in EB. Currently it is unknown whether this manipulation of energy intake is ideal for maximal fat loss and FFM retention or if additional arrangements of ER and refeeds may be superior.

- Coordinating refeed periods. It may be advantageous to synchronise intervals of EB with outcome-focused or high-volume training periods. This tactic may allow the athlete to perform optimally during training sessions by providing additional nutritional support and negating the adverse consequences of sustained, daily ER.

- High protein intake. High protein intakes may be beneficial to an athlete during IER by reducing FFM losses, providing greater satiety and increasing energy expenditure through the thermic effect of feeding. A daily protein intake range between 2.3 and $3.1 \mathrm{~g} / \mathrm{kg}$ of lean body mass (which equates to approximately 2.0-2.6 g per kg of absolute body mass for an $80 \mathrm{~kg}$ athlete with $15 \%$ body fat) is likely an appropriate practical recommendation for athletes undergoing IER with concurrent resistance exercise.

- Emphasizing carbohydrate intake during refeeds. Although yet to be confirmed, it seems wise to place emphasis on increasing intake of carbohydrate during refeed periods opposed to increasing protein or fat. Elevated levels of leptin following carbohydrate feeding may cause stimulatory effects on energy expenditure and suppress appetite, leading to greater fat loss efficiency and easier diet adherence. Greater carbohydrate availability during refeed periods may also result in more pronounced anabolic responses when IER is applied in concert with resistance exercise, potentially reducing FFM losses during ER.

Author Contributions: Conceptualization, J.J.P.; methodology, J.J.P. and E.R.H.; investigation, analysis, draft preparation, writing and editing, J.J.P., E.R.H., L.E.N., A.J.G. and P.F. 
Funding: This work is supported in part by Renaissance Periodisation and by the Australian Department of Education and Training via a Research Training Program Scholarship awarded to J.J.P.

Acknowledgments: We would also like to thank Bill Campbell from the University of South Florida for providing feedback on this manuscript, and Keith Kraker for designing the figures used in this paper.

Conflicts of Interest: L.E.N. is an author of The Complete Contest Prep Guide, an eBook designed to help physique athletes prepare for competition. E.R.H. is the chief author of The Muscle and Strength Nutrition Pyramid, an eBook that outlines evidence-based strategies to improve strength and body composition.

\section{References}

1. Manore, M.M. Weight Management for Athletes and Active Individuals: A Brief Review. Sports Med. 2015, 45 (Suppl. 1), S83-S92. [CrossRef]

2. Trexler, E.T.; Smith-Ryan, A.E.; Norton, L.E. Metabolic adaptation to weight loss: Implications for the athlete. J. Int. Soc. Sports Nutr. 2014, 11, 7. [CrossRef]

3. Franchini, E.; Brito, C.J.; Artioli, G.G. Weight loss in combat sports: Physiological, psychological and performance effects. J. Int. Soc. Sports Nutr. 2012, 9, 52. [CrossRef]

4. Slater, G.; Rice, A.; Jenkins, D.; Hahn, A. Body mass management of lightweight rowers: Nutritional strategies and performance implications. Br. J. Sports Med. 2014, 48, 1529-1533. [CrossRef]

5. Pettersson, S.; Pipping Ekstrom, M.; Berg, C.M. The food and weight combat. A problematic fight for the elite combat sports athlete. Appetite 2012, 59, 234-242. [CrossRef]

6. Wilson, G.; Hawken, M.B.; Poole, I.; Sparks, A.; Bennett, S.; Drust, B.; Morton, J.; Close, G.L. Rapid weight-loss impairs simulated riding performance and strength in jockeys: Implications for making-weight. J. Sports Sci. 2014, 32, 383-391. [CrossRef]

7. Brito, C.J.; Roas, A.F.C.M.; Brito, I.S.S.; Marins, J.C.B.; Córdova, C.; Franchini, E. Methods of body mass reduction by combat sport athletes. Int. J. Sport Nutr. Exerc. Metab. 2012, 22, 89-97. [CrossRef]

8. $\quad$ Langan-Evans, C.; Close, G.L.; Morton, J.P. Making weight in combat sports. Strength Cond. J. 2011, 33, 25-39. [CrossRef]

9. Varady, K.A. Intermittent versus daily calorie restriction: Which diet regimen is more effective for weight loss? Obes. Rev. Off. J. Int. Assoc. Study Obes. 2011, 12, e593-e601. [CrossRef]

10. Dixon, J.B.; Lambert, E.A.; Grima, M.; Rice, T.; Lambert, G.W.; Straznicky, N.E. Fat-free mass loss generated with weight loss in overweight and obese adults: What may we expect? Diabetes Obes. Metab. 2015, 17, 91-93. [CrossRef]

11. Kouda, K.; Nakamura, H.; Kohno, H.; Okuda, T.; Higashine, Y.; Hisamori, K.; Ishihara, H.; Tokunaga, R.; Sonoda, Y. Metabolic response to short-term 4-day energy restriction in a controlled study. Environ. Health Prev. Med. 2006, 11, 89-92. [CrossRef]

12. MacLean, P.S.; Higgins, J.A.; Giles, E.D.; Sherk, V.D.; Jackman, M.R. The role for adipose tissue in weight regain after weight loss. Obes. Rev. Off. J. Int. Assoc. Study Obes. 2015, 16 (Suppl. 1), 45-54. [CrossRef]

13. Maestu, J.; Eliakim, A.; Jurimae, J.; Valter, I.; Jurimae, T. Anabolic and catabolic hormones and energy balance of the male bodybuilders during the preparation for the competition. J. Strength Cond. Res. 2010, 24, 1074-1081. [CrossRef]

14. Maestu, J.; Jurimae, J.; Valter, I.; Jurimae, T. Increases in ghrelin and decreases in leptin without altering adiponectin during extreme weight loss in male competitive bodybuilders. Metab. Clin. Exp. 2008, 57, 221-225. [CrossRef]

15. Sloth, B.; Due, A.; Larsen, T.M.; Holst, J.J.; Heding, A.; Astrup, A. The effect of a high-MUFA, low-glycaemic index diet and a low-fat diet on appetite and glucose metabolism during a 6-month weight maintenance period. Br. J. Nutr. 2009, 101, 1846-1858. [CrossRef]

16. Donnelly, J.E.; Blair, S.N.; Jakicic, J.M.; Manore, M.M.; Rankin, J.W.; Smith, B.K. American College of Sports Medicine Position Stand. Appropriate physical activity intervention strategies for weight loss and prevention of weight regain for adults. Med. Sci. Sports Exerc. 2009, 41, 459-471. [CrossRef]

17. Mountjoy, M.; Junge, A.; Benjamen, S.; Boyd, K.; Diop, M.; Gerrard, D.; van den Hoogenband, C.R.; Marks, S.; Martinez-Ruiz, E.; Miller, J.; et al. Competing with injuries: Injuries prior to and during the 15th FINA World Championships 2013 (aquatics). Br. J. Sports Med. 2015, 49, 37-43. [CrossRef] 
18. Mountjoy, M.; Sundgot-Borgen, J.; Burke, L.; Carter, S.; Constantini, N.; Lebrun, C.; Meyer, N.; Sherman, R.; Steffen, K.; Budgett, R.; et al. The IOC consensus statement: Beyond the Female Athlete Triad-Relative Energy Deficiency in Sport (RED-S). Br. J. Sports Med. 2014, 48, 491-497. [CrossRef]

19. Sundgot-Borgen, J.; Garthe, I. Elite athletes in aesthetic and Olympic weight-class sports and the challenge of body weight and body compositions. J. Sports Sci. 2011, 29 (Suppl. 1), S101-S114. [CrossRef]

20. Pettersson, S.; Ekström, M.P.; Berg, C.M. Practices of weight regulation among elite athletes in combat sports: A matter of mental advantage? J. Athl. Train. 2013, 48, 99-108. [CrossRef]

21. Aragon, A.A.; Schoenfeld, B.J.; Wildman, R.; Kleiner, S.; VanDusseldorp, T.; Taylor, L.; Earnest, C.P.; Arciero, P.J.; Wilborn, C.; Kalman, D.S.; et al. International society of sports nutrition position stand: Diets and body composition. J. Int. Soc. Sports Nutr. 2017, 14, 16. [CrossRef]

22. Byrne, N.M.; Sainsbury, A.; King, N.A.; Hills, A.P.; Wood, R.E. Intermittent energy restriction improves weight loss efficiency in obese men: The MATADOR study. Int. J. Obes. 2017. [CrossRef]

23. Harris, L.; McGarty, A.; Hutchison, L.; Ells, L.; Hankey, C. Short-term intermittent energy restriction interventions for weight management: A systematic review and meta-analysis. Obes. Rev. Off. J. Int. Assoc. Study Obes. 2018, 19, 1-13. [CrossRef]

24. Harvie, M.; Howell, A. Potential Benefits and Harms of Intermittent Energy Restriction and Intermittent Fasting Amongst Obese, Overweight and Normal Weight Subjects-A Narrative Review of Human and Animal Evidence. Behav. Sci. 2017, 7, 4. [CrossRef]

25. Trepanowski, J.F.; Kroeger, C.M.; Barnosky, A.; Klempel, M.C.; Bhutani, S.; Hoddy, K.K.; Gabel, K.; Freels, S.; Rigdon, J.; Rood, J.; et al. Effect of Alternate-Day Fasting on Weight Loss, Weight Maintenance, and Cardioprotection Among Metabolically Healthy Obese Adults: A Randomized Clinical Trial. JAMA Intern. Med. 2017, 177, 930-938. [CrossRef]

26. Trepanowski, J.F.; Kroeger, C.M.; Barnosky, A.; Klempel, M.C.; Bhutani, S.; Hoddy, K.K.; Rood, J.; Ravussin, E.; Varady, K.A. Effects of alternate-day fasting or daily calorie restriction on body composition, fat distribution, and circulating adipokines: Secondary analysis of a randomized controlled trial. Clin. Nutr. 2017, 37, 1871-1878. [CrossRef]

27. Seimon, R.V.; Shi, Y.C.; Slack, K.; Lee, K.; Fernando, H.A.; Nguyen, A.D.; Zhang, L.; Lin, S.; Enriquez, R.F.; Lau, J.; et al. Intermittent Moderate Energy Restriction Improves Weight Loss Efficiency in Diet-Induced Obese Mice. PLoS ONE 2016, 11, e0145157. [CrossRef]

28. Wing, R.R.; Jeffery, R.W. Prescribed "breaks" as a means to disrupt weight control efforts. Obes. Res. 2003, 11, 287-291. [CrossRef]

29. Seimon, R.V.; Roekenes, J.A.; Zibellini, J.; Zhu, B.; Gibson, A.A.; Hills, A.P.; Wood, R.E.; King, N.A.; Byrne, N.M.; Sainsbury, A. Do intermittent diets provide physiological benefits over continuous diets for weight loss? A systematic review of clinical trials. Mol. Cell. Endocrinol. 2015, 418 Pt 2, 153-172. [CrossRef]

30. Mettler, S.; Mitchell, N.; Tipton, K.D. Increased protein intake reduces lean body mass loss during weight loss in athletes. Med. Sci. Sports Exerc. 2010, 42, 326-337. [CrossRef]

31. Elia, M.; Stubbs, R.J.; Henry, C.J. Differences in fat, carbohydrate, and protein metabolism between lean and obese subjects undergoing total starvation. Obes. Res. 1999, 7, 597-604. [CrossRef]

32. Suryanarayana, B.V.; Kent, J.R.; Meister, L.; Parlow, A.F. Pituitary-gonadal axis during prolonged total starvation in obese men. Am. J. Clin. Nutr. 1969, 22, 767-770. [CrossRef]

33. Heymsfield, S.B.; Gonzalez, M.C.; Shen, W.; Redman, L.; Thomas, D. Weight loss composition is one-fourth fat-free mass: A critical review and critique of this widely cited rule. Obes. Rev. Off. J. Int. Assoc. Study Obes. 2014, 15, 310-321. [CrossRef]

34. Rosenbaum, M.; Kissileff, H.R.; Mayer, L.E.; Hirsch, J.; Leibel, R.L. Energy intake in weight-reduced humans. Brain Res. 2010, 1350, 95-102. [CrossRef]

35. Rosenbaum, M.; Leibel, R.L. Adaptive thermogenesis in humans. Int. J. Obes. 2010, 34 (Suppl. 1), S47-S55. [CrossRef]

36. Doucet, E.; Imbeault, P.; St-Pierre, S.; Almeras, N.; Mauriege, P.; Despres, J.P.; Bouchard, C.; Tremblay, A. Greater than predicted decrease in energy expenditure during exercise after body weight loss in obese men. Clin. Sci. 2003, 105, 89-95. [CrossRef]

37. Doucet, E.; St-Pierre, S.; Almeras, N.; Despres, J.P.; Bouchard, C.; Tremblay, A. Evidence for the existence of adaptive thermogenesis during weight loss. Br. J. Nutr. 2001, 85, 715-723. [CrossRef] 
38. Goele, K.; Bosy-Westphal, A.; Rumcker, B.; Lagerpusch, M.; Muller, M.J. Influence of changes in body composition and adaptive thermogenesis on the difference between measured and predicted weight loss in obese women. Obes. Facts 2009, 2, 105-109. [CrossRef]

39. Anderson, J.W.; Konz, E.C.; Frederich, R.C.; Wood, C.L. Long-term weight-loss maintenance: A meta-analysis of US studies. Am. J. Clin. Nutr. 2001, 74, 579-584. [CrossRef]

40. Tobey, J.A. The Biology of Human Starvation. Am. J. Public Health Nations Health 1951, 41, 236-237. [CrossRef]

41. Weigle, D.S.; Brunzell, J.D. Assessment of energy expenditure in ambulatory reduced-obese subjects by the techniques of weight stabilization and exogenous weight replacement. Int. J. Obes. 1990, 14 (Suppl. 1), 69-77; discussion 77-81.

42. Weigle, D.S.; Sande, K.J.; Iverius, P.H.; Monsen, E.R.; Brunzell, J.D. Weight loss leads to a marked decrease in nonresting energy expenditure in ambulatory human subjects. Metab. Clin. Exp. 1988, 37, 930-936. [CrossRef]

43. Weyer, C.; Hanson, K.; Bogardus, C.; Pratley, R.E. Long-term changes in insulin action and insulin secretion associated with gain, loss, regain and maintenance of body weight. Diabetologia 2000, 43, 36-46. [CrossRef]

44. Weyer, C.; Pratley, R.E.; Salbe, A.D.; Bogardus, C.; Ravussin, E.; Tataranni, P.A. Energy expenditure, fat oxidation, and body weight regulation: A study of metabolic adaptation to long-term weight change. J. Clin. Endocrinol. Metab. 2000, 85, 1087-1094. [CrossRef]

45. Weyer, C.; Walford, R.L.; Harper, I.T.; Milner, M.; MacCallum, T.; Tataranni, P.A.; Ravussin, E. Energy metabolism after 2 y of energy restriction: The biosphere 2 experiment. Am. J. Clin. Nutr. 2000, 72, 946-953. [CrossRef]

46. Miles, C.W.; Wong, N.P.; Rumpler, W.V.; Conway, J. Effect of circadian variation in energy expenditure, within-subject variation and weight reduction on thermic effect of food. Eur. J. Clin. Nutr. 1993, 47, 274-284.

47. Kim, H.J.; Lee, S.; Kim, T.W.; Kim, H.H.; Jeon, T.Y.; Yoon, Y.S.; Oh, S.W.; Kwak, H.; Lee, J.G. Effects of exercise-induced weight loss on acylated and unacylated ghrelin in overweight children. Clin. Endocrinol. 2008, 68, 416-422. [CrossRef]

48. Silva, J.E. The thermogenic effect of thyroid hormone and its clinical implications. Ann. Intern. Med. 2003, 139, 205-213. [CrossRef]

49. Sainsbury, A.; Zhang, L. Role of the hypothalamus in the neuroendocrine regulation of body weight and composition during energy deficit. Obes. Rev. Off. J. Int. Assoc. Study Obes. 2012, 13, 234-257. [CrossRef]

50. Warren, M.P. Endocrine manifestations of eating disorders. J. Clin. Endocrinol. Metab. 2011, 96, $333-343$. [CrossRef]

51. Rossow, L.M.; Fukuda, D.H.; Fahs, C.A.; Loenneke, J.P.; Stout, J.R. Natural bodybuilding competition preparation and recovery: A 12-month case study. Int. J. Sports Physiol. Perform. 2013, 8, 582-592. [CrossRef]

52. Sainsbury, A.; Zhang, L. Role of the arcuate nucleus of the hypothalamus in regulation of body weight during energy deficit. Mol. Cell. Endocrinol. 2010, 316, 109-119. [CrossRef]

53. Margetic, S.; Gazzola, C.; Pegg, G.G.; Hill, R.A. Leptin: A review of its peripheral actions and interactions. Int. J. Obes. Relat. Metab. Disord. 2002, 26, 1407-1433. [CrossRef]

54. Pandit, R.; Beerens, S.; Adan, R.A.H. Role of leptin in energy expenditure: The hypothalamic perspective. Am. J. Physiol. Regul. Integr. Comp. Physiol. 2017, 312, R938-R947. [CrossRef]

55. Hagmar, M.; Berglund, B.; Brismar, K.; Hirschberg, A.L. Body composition and endocrine profile of male Olympic athletes striving for leanness. Clin. J. Sport Med. 2013, 23, 197-201. [CrossRef]

56. Muller, M.J.; Enderle, J.; Pourhassan, M.; Braun, W.; Eggeling, B.; Lagerpusch, M.; Gluer, C.C.; Kehayias, J.J.; Kiosz, D.; Bosy-Westphal, A. Metabolic adaptation to caloric restriction and subsequent refeeding: The Minnesota Starvation Experiment revisited. Am. J. Clin. Nutr. 2015, 102, 807-819. [CrossRef]

57. Koehler, K.; Hoerner, N.R.; Gibbs, J.C.; Zinner, C.; Braun, H.; De Souza, M.J.; Schaenzer, W. Low energy availability in exercising men is associated with reduced leptin and insulin but not with changes in other metabolic hormones. J. Sports Sci. 2016, 34, 1921-1929. [CrossRef]

58. Rosenbaum, M.; Goldsmith, R.; Bloomfield, D.; Magnano, A.; Weimer, L.; Heymsfield, S.; Gallagher, D.; Mayer, L.; Murphy, E.; Leibel, R.L. Low-dose leptin reverses skeletal muscle, autonomic, and neuroendocrine adaptations to maintenance of reduced weight. J. Clin. Investig. 2005, 115, 3579-3586. [CrossRef]

59. Ariyasu, H.; Takaya, K.; Tagami, T.; Ogawa, Y.; Hosoda, K.; Akamizu, T.; Suda, M.; Koh, T.; Natsui, K.; Toyooka, S.; et al. Stomach is a major source of circulating ghrelin, and feeding state determines plasma ghrelin-like immunoreactivity levels in humans. J. Clin. Endocrinol. Metab. 2001, 86, 4753-4758. [CrossRef] 
60. Gil-Campos, M.; Aguilera, C.M.; Canete, R.; Gil, A. Ghrelin: A hormone regulating food intake and energy homeostasis. Br. J. Nutr. 2006, 96, 201-226. [CrossRef]

61. Labayen, I.; Ortega, F.B.; Ruiz, J.R.; Lasa, A.; Simon, E.; Margareto, J. Role of baseline leptin and ghrelin levels on body weight and fat mass changes after an energy-restricted diet intervention in obese women: Effects on energy metabolism. J. Clin. Endocrinol. Metab. 2011, 96, E996-E1000. [CrossRef]

62. Rooyackers, O.E.; Nair, K.S. Hormonal regulation of human muscle protein metabolism. Annu. Rev. Nutr. 1997, 17, 457-485. [CrossRef]

63. de Luis, D.A.; Sagrado, M.G.; Conde, R.; Aller, R.; Izaola, O. The effects of two different hypocaloric diets on glucagon-like peptide 1 in obese adults, relation with insulin response after weight loss. J. Diabetes Its Complicat. 2009, 23, 239-243. [CrossRef]

64. Hietaniemi, M.; Jokela, M.; Rantala, M.; Ukkola, O.; Vuoristo, J.T.; Ilves, M.; Rysa, J.; Kesaniemi, Y. The effect of a short-term hypocaloric diet on liver gene expression and metabolic risk factors in obese women. Nutr. Metab. Cardiovasc. Dis. NMCD 2009, 19, 177-183. [CrossRef]

65. Keim, N.L.; Stern, J.S.; Havel, P.J. Relation between circulating leptin concentrations and appetite during a prolonged, moderate energy deficit in women. Am. J. Clin. Nutr. 1998, 68, 794-801. [CrossRef]

66. Lien, L.F.; Haqq, A.M.; Arlotto, M.; Slentz, C.A.; Muehlbauer, M.J.; McMahon, R.L.; Rochon, J.; Gallup, D.; Bain, J.R.; Ilkayeva, O.; et al. The STEDMAN project: Biophysical, biochemical and metabolic effects of a behavioral weight loss intervention during weight loss, maintenance, and regain. OMICS J. Integr. Biol. 2009, 13, 21-35. [CrossRef]

67. Strohacker, K.; McCaffery, J.M.; MacLean, P.S.; Wing, R.R. Adaptations of leptin, ghrelin or insulin during weight loss as predictors of weight regain: A review of current literature. Int. J. Obes. 2014, 38, 388-396. [CrossRef]

68. Ivy, J.L. Regulation of muscle glycogen repletion, muscle protein synthesis and repair following exercise. J. Sports Sci. Med. 2004, 3, 131-138.

69. Friedl, K.E.; Moore, R.J.; Hoyt, R.W.; Marchitelli, L.J.; Martinez-Lopez, L.E.; Askew, E.W. Endocrine markers of semistarvation in healthy lean men in a multistressor environment. J. Appl. Physiol. 2000, 88, 1820-1830. [CrossRef]

70. De Maddalena, C.; Vodo, S.; Petroni, A.; Aloisi, A.M. Impact of testosterone on body fat composition. J. Cell Physiol. 2012, 227, 3744-3748. [CrossRef]

71. Mah, P.M.; Wittert, G.A. Obesity and testicular function. Mol. Cell. Endocrinol. 2010, 316, 180-186. [CrossRef]

72. Smith, W.J.; Underwood, L.E.; Clemmons, D.R. Effects of caloric or protein restriction on insulin-like growth factor-I (IGF-I) and IGF-binding proteins in children and adults. J. Clin. Endocrinol. Metab. 1995, 80, 443-449.

73. Redman, L.M.; Veldhuis, J.D.; Rood, J.; Smith, S.R.; Williamson, D.; Ravussin, E.; Pennington, C.T. The effect of caloric restriction interventions on growth hormone secretion in nonobese men and women. Aging Cell 2010, 9, 32-39. [CrossRef]

74. Simmons, P.S.; Miles, J.M.; Gerich, J.E.; Haymond, M.W. Increased proteolysis. An effect of increases in plasma cortisol within the physiologic range. J. Clin. Investig. 1984, 73, 412-420. [CrossRef]

75. Zakrzewska, K.E.; Cusin, I.; Sainsbury, A.; Rohner-Jeanrenaud, F.; Jeanrenaud, B. Glucocorticoids as counterregulatory hormones of leptin: Toward an understanding of leptin resistance. Diabetes 1997, 46, 717-719. [CrossRef]

76. Mastorakos, G.; Pavlatou, M. Exercise as a stress model and the interplay between the hypothalamus-pituitary-adrenal and the hypothalamus-pituitary-thyroid axes. Horm. Metab. Res. 2005, 37, 577-584. [CrossRef]

77. Georgopoulos, N.A.; Rottstein, L.; Tsekouras, A.; Theodoropoulou, A.; Koukkou, E.; Mylonas, P.; Polykarpou, G.; Lampropoulou, E.; Iconomou, G.; Leglise, M.; et al. Abolished circadian rhythm of salivary cortisol in elite artistic gymnasts. Steroids 2011, 76, 353-357. [CrossRef]

78. Seimon, R.V.; Hostland, N.; Silveira, S.L.; Gibson, A.A.; Sainsbury, A. Effects of energy restriction on activity of the hypothalamo-pituitary-adrenal axis in obese humans and rodents: Implications for diet-induced changes in body composition. Horm. Mol. Biol. Clin. Investig. 2013, 15, 71-80. [CrossRef]

79. MacLean, P.S.; Higgins, J.A.; Jackman, M.R.; Johnson, G.C.; Fleming-Elder, B.K.; Wyatt, H.R.; Melanson, E.L.; Hill, J.O. Peripheral metabolic responses to prolonged weight reduction that promote rapid, efficient regain in obesity-prone rats. Am. J. Physiol. Regul. Integr. Comp. Physiol. 2006, 290, R1577-R1588. [CrossRef] 
80. MacLean, P.S.; Higgins, J.A.; Wyatt, H.R.; Melanson, E.L.; Johnson, G.C.; Jackman, M.R.; Giles, E.D.; Brown, I.E.; Hill, J.O. Regular exercise attenuates the metabolic drive to regain weight after long-term weight loss. Am. J. Physiol. Regul. Integr. Comp. Physiol. 2009, 297, R793-R802. [CrossRef]

81. Gurr, M.I.; Jung, R.T.; Robinson, M.P.; James, W.P. Adipose tissue cellularity in man: The relationship between fat cell size and number, the mass and distribution of body fat and the history of weight gain and loss. Int. J. Obes. 1982, 6, 419-436.

82. Portillo, M.P.; Cantoral, R.; Macarulla, M.T. Effects of dietary fat content on adiposity during energy restriction in genetically obese rats. Reprod. Nutr. Dev. 1999, 39, 189-199. [CrossRef]

83. Jacobsson, B.; Smith, U. Effect of cell size on lipolysis and antilipolytic action of insulin in human fat cells. J. Lipid Res. 1972, 13, 651-656.

84. Olefsky, J.M. Effects of fasting on insulin binding, glucose transport, and glucose oxidation in isolated rat adipocytes: Relationships between insulin receptors and insulin action. J. Clin. Investig. 1976, 58, 1450-1460. [CrossRef]

85. Bjorntorp, P.; Carlgren, G.; Isaksson, B.; Krotkiewski, M.; Larsson, B.; Sjostrom, L. Effect of an energy-reduced dietary regimen in relation to adipose tissue cellularity in obese women. Am. J. Clin. Nutr. 1975, 28, 445-452. [CrossRef]

86. Lofgren, P.; Hoffstedt, J.; Naslund, E.; Wiren, M.; Arner, P. Prospective and controlled studies of the actions of insulin and catecholamine in fat cells of obese women following weight reduction. Diabetologia 2005, 48, 2334-2342. [CrossRef]

87. Svensson, P.A.; Gabrielsson, B.G.; Jernas, M.; Gummesson, A.; Sjoholm, K. Regulation of human aldoketoreductase 1C3 (AKR1C3) gene expression in the adipose tissue. Cell. Mol. Biol. Lett. 2008, 13, 599-613. [CrossRef]

88. Lee, M.J.; Wu, Y.; Fried, S.K. Adipose tissue remodeling in pathophysiology of obesity. Curr. Opin. Clin. Nutr. Metab. Care 2010, 13, 371-376. [CrossRef]

89. Mariman, E.C. Human biology of weight maintenance after weight loss. J. Nutr. Nutr. 2012, 5, 13-25. [CrossRef]

90. Spalding, K.L.; Arner, E.; Westermark, P.O.; Bernard, S.; Buchholz, B.A.; Bergmann, O.; Blomqvist, L.; Hoffstedt, J.; Naslund, E.; Britton, T.; et al. Dynamics of fat cell turnover in humans. Nature 2008, 453, 783-787. [CrossRef]

91. Jackman, M.R.; Steig, A.; Higgins, J.A.; Johnson, G.C.; Fleming-Elder, B.K.; Bessesen, D.H.; MacLean, P.S. Weight regain after sustained weight reduction is accompanied by suppressed oxidation of dietary fat and adipocyte hyperplasia. Am. J. Physiol. Regul. Integr. Comp. Physiol. 2008, 294, R1117-R1129. [CrossRef]

92. Barnosky, A.R.; Hoddy, K.K.; Unterman, T.G.; Varady, K.A. Intermittent fasting vs daily calorie restriction for type 2 diabetes prevention: A review of human findings. Transl. Res. 2014, 164, 302-311. [CrossRef]

93. Moro, T.; Tinsley, G.; Bianco, A.; Marcolin, G.; Pacelli, Q.F.; Battaglia, G.; Palma, A.; Gentil, P.; Neri, M.; Paoli, A. Effects of eight weeks of time-restricted feeding (16/8) on basal metabolism, maximal strength, body composition, inflammation, and cardiovascular risk factors in resistance-trained males. J. Transl. Med. 2016, 14, 290. [CrossRef]

94. Varady, K.A.; Allister, C.A.; Roohk, D.J.; Hellerstein, M.K. Improvements in body fat distribution and circulating adiponectin by alternate-day fasting versus calorie restriction. J. Nutr. Biochem. 2010, 21, 188-195. [CrossRef]

95. Varady, K.A.; Bhutani, S.; Church, E.C.; Klempel, M.C. Short-term modified alternate-day fasting: A novel dietary strategy for weight loss and cardioprotection in obese adults. Am. J. Clin. Nutr. 2009, 90, 1138-1143. [CrossRef]

96. Varady, K.A.; Bhutani, S.; Klempel, M.C.; Kroeger, C.M.; Trepanowski, J.F.; Haus, J.M.; Hoddy, K.K.; Calvo, Y. Alternate day fasting for weight loss in normal weight and overweight subjects: A randomized controlled trial. Nutr. J. 2013, 12, 146. [CrossRef]

97. Davis, C.S.; Clarke, R.E.; Coulter, S.N.; Rounsefell, K.N.; Walker, R.E.; Rauch, C.E.; Huggins, C.E.; Ryan, L. Intermittent energy restriction and weight loss: A systematic review. Eur. J. Clin. Nutr. 2016, 70, 292-299. [CrossRef]

98. Davoodi, S.H.; Ajami, M.; Ayatollahi, S.A.; Dowlatshahi, K.; Javedan, G.; Pazoki-Toroudi, H.R. Calorie shifting diet versus calorie restriction diet: A comparative clinical trial study. Int. J. Prev. Med. 2014, 5, $447-456$. 
99. Harris, L.; Hamilton, S.; Azevedo, L.B.; Olajide, O.J.; De Brun, C.; Waller, G.; Whittaker, V.J.; Sharp, T.; Lean, M.; Hankey, C.; et al. Intermittent fasting interventions for the treatment of overweight and obesity in adults aged 18 years and over: A systematic review and meta-analysis. JBI Database Syst. Rev. Implement. Rep. 2018, 16, 507-547. [CrossRef]

100. Campbell, B.I.; Aguilar, D.; Colenso-Semple, L.; Hartke, K.; Gai, C.; Gaviria, D.; Gorman, J.; Rubio, J.; Ibrahim, A.; Barker, B. The effects of intermittent carbohydrate re-feeds vs. continuous dieting on body composition in resistance trained individuals: A flexible dieting study. In Proceedings of the 15th International Society of Sports Nutrition (ISSN) Conference and Expo, Clearwater Beach, FL, USA, 7-9 June 2018.

101. Campbell, B.I.; Aguilar, D.; Wong, V.; Rogers, G.; Fox, C.; Hosey, T.; Lindsay, S.; Ford, S.; Radford, D. The effects of intermittent carbohydrate re-feeds vs. continuous dieting on resting metabolic rate in resistance trained individuals: A flexible dieting study. In Proceedings of the 15th International Society of Sports Nutrition (ISSN) Conference and Expo, Clearwater Beach, FL, USA, 7-9 June 2018.

102. Coelho do Vale, R.; Pieters, R.; Zeelenberg, M. The benefits of behaving badly on occasion: Successful regulation by planned hedonic deviations. J. Consum. Psychol. 2016, 26, 17-28. [CrossRef]

103. Keogh, J.B.; Pedersen, E.; Petersen, K.S.; Clifton, P.M. Effects of intermittent compared to continuous energy restriction on short-term weight loss and long-term weight loss maintenance. Clin. Obes. 2014, 4, 150-156. [CrossRef]

104. Bosy-Westphal, A.; Schautz, B.; Lagerpusch, M.; Pourhassan, M.; Braun, W.; Goele, K.; Heller, M.; Glüer, C.C.; Müller, M.J. Effect of weight loss and regain on adipose tissue distribution, composition of lean mass and resting energy expenditure in young overweight and obese adults. Int. J. Obes. 2013, 37, 1371. [CrossRef]

105. Ravussin, E.; Lillioja, S.; Knowler, W.C.; Christin, L.; Freymond, D.; Abbott, W.G.H.; Boyce, V.; Howard, B.V.; Bogardus, C. Reduced Rate of Energy Expenditure as a Risk Factor for Body-Weight Gain. N. Engl. J. Med. 1988, 318, 467-472. [CrossRef]

106. Peos, J.J.; Helms, E.R.; Fournier, P.A.; Sainsbury, A. Continuous versus intermittent moderate energy restriction for increased fat mass loss and fat free mass retention in adult athletes: Protocol for a randomised controlled trial-the ICECAP trial (Intermittent versus Continuous Energy restriction Compared in an Athlete Population). BMJ Open Sport Exerc. Med. 2018, 4, e000423. [PubMed]

107. Henry, R.R.; Scheaffer, L.; Olefsky, J.M. Glycemic effects of intensive caloric restriction and isocaloric refeeding in noninsulin-dependent diabetes mellitus. J. Clin. Endocrinol. Metab. 1985, 61, 917-925. [CrossRef]

108. Wing, R.R.; Blair, E.H.; Bononi, P.; Marcus, M.D.; Watanabe, R.; Bergman, R.N. Caloric restriction per se is a significant factor in improvements in glycemic control and insulin sensitivity during weight loss in obese NIDDM patients. Diabetes Care 1994, 17, 30-36. [CrossRef]

109. Collet, T.H.; Sonoyama, T.; Henning, E.; Keogh, J.M.; Ingram, B.; Kelway, S.; Guo, L.; Farooqi, I.S. A Metabolomic Signature of Acute Caloric Restriction. J. Clin. Endocrinol. Metab. 2017, 102, 4486-4495. [CrossRef] [PubMed]

110. Dulloo, A.G.; Jacquet, J. Adaptive reduction in basal metabolic rate in response to food deprivation in humans: A role for feedback signals from fat stores. Am. J. Clin. Nutr. 1998, 68, 599-606. [CrossRef]

111. Kolaczynski, J.W.; Considine, R.V.; Ohannesian, J.; Marco, C.; Opentanova, I.; Nyce, M.R.; Myint, M.; Caro, J.F. Responses of leptin to short-term fasting and refeeding in humans: A link with ketogenesis but not ketones themselves. Diabetes 1996, 45, 1511-1515. [CrossRef] [PubMed]

112. Schebendach, J.E.; Golden, N.H.; Jacobson, M.S.; Hertz, S.; Shenker, I.R. The metabolic responses to starvation and refeeding in adolescents with anorexia nervosa. Ann. N. Y. Acad. Sci. 1997, 817, 110-119. [CrossRef]

113. Tsintzas, K.; Jewell, K.; Kamran, M.; Laithwaite, D.; Boonsong, T.; Littlewood, J.; Macdonald, I.; Bennett, A. Differential regulation of metabolic genes in skeletal muscle during starvation and refeeding in humans. J. Physiol. 2006, 575, 291-303. [CrossRef] [PubMed]

114. Weinsier, R.L.; Nagy, T.R.; Hunter, G.R.; Darnell, B.E.; Hensrud, D.D.; Weiss, H.L. Do adaptive changes in metabolic rate favor weight regain in weight-reduced individuals? An examination of the set-point theory. Am. J. Clin. Nutr. 2000, 72, 1088-1094. [CrossRef] [PubMed]

115. Mathieson, R.A.; Walberg, J.L.; Gwazdauskas, F.C.; Hinkle, D.E.; Gregg, J.M. The effect of varying carbohydrate content of a very-low-caloric diet on resting metabolic rate and thyroid hormones. Metab. Clin. Exp. 1986, 35, 394-398. [CrossRef] 
116. Chin-Chance, C.; Polonsky, K.S.; Schoeller, D.A. Twenty-four-hour leptin levels respond to cumulative short-term energy imbalance and predict subsequent intake. J. Clin. Endocrinol. Metab. 2000, 85, 2685-2691. [CrossRef] [PubMed]

117. Douyon, L.; Schteingart, D.E. Effect of obesity and starvation on thyroid hormone, growth hormone, and cortisol secretion. Endocrinol. Metab. Clin N. Am. 2002, 31, 173-189. [CrossRef]

118. Dirlewanger, M.; di Vetta, V.; Guenat, E.; Battilana, P.; Seematter, G.; Schneiter, P.; Jequier, E.; Tappy, L. Effects of short-term carbohydrate or fat overfeeding on energy expenditure and plasma leptin concentrations in healthy female subjects. Int. J. Obes. Relat. Metab. Disord. 2000, 24, 1413-1418. [CrossRef]

119. Mitchell, L.; Hackett, D.; Gifford, J.; Estermann, F.; O'Connor, H. Do Bodybuilders Use Evidence-Based Nutrition Strategies to Manipulate Physique? Sports 2017, 5, 76. [CrossRef]

120. Helms, E.R.; Fitschen, P.J.; Aragon, A.A.; Cronin, J.; Schoenfeld, B.J. Recommendations for natural bodybuilding contest preparation: Resistance and cardiovascular training. J. Sports Med. Phys. Fit. 2015, 55, 164-178.

121. Kistler, B.M.; Fitschen, P.J.; Ranadive, S.M.; Fernhall, B.; Wilund, K.R. Case study: Natural bodybuilding contest preparation. Int. J. Sport Nutr. Exerc. Metab. 2014, 24, 694-700. [CrossRef]

122. Nindl, B.C.; Barnes, B.R.; Alemany, J.A.; Frykman, P.N.; Shippee, R.L.; Friedl, K.E. Physiological consequences of U.S. Army Ranger training. Med. Sci. Sports Exerc. 2007, 39, 1380-1387. [CrossRef]

123. Koutedakis, Y.; Pacy, P.J.; Quevedo, R.M.; Millward, D.J.; Hesp, R.; Boreham, C.; Sharp, N.C. The effects of two different periods of weight-reduction on selected performance parameters in elite lightweight oarswomen. Int. J. Sports Med. 1994, 15, 472-477. [CrossRef] [PubMed]

124. Campbell, W.W.; Haub, M.D.; Wolfe, R.R.; Ferrando, A.A.; Sullivan, D.H.; Apolzan, J.W.; Iglay, H.B. Resistance training preserves fat-free mass without impacting changes in protein metabolism after weight loss in older women. Obesity 2009, 17, 1332-1339. [CrossRef] [PubMed]

125. Verreijen, A.M.; Engberink, M.F.; Memelink, R.G.; van der Plas, S.E.; Visser, M.; Weijs, P.J. Effect of a high protein diet and/or resistance exercise on the preservation of fat free mass during weight loss in overweight and obese older adults: A randomized controlled trial. Nutr. J. 2017, 16. [CrossRef]

126. Bryner, R.W.; Ullrich, I.H.; Sauers, J.; Donley, D.; Hornsby, G.; Kolar, M.; Yeater, R. Effects of resistance vs. aerobic training combined with an 800 calorie liquid diet on lean body mass and resting metabolic rate. J. Am. Coll. Nutr. 1999, 18, 115-121. [CrossRef] [PubMed]

127. Garthe, I.; Raastad, T.; Refsnes, P.E.; Koivisto, A.; Sundgot-Borgen, J. Effect of two different weight-loss rates on body composition and strength and power-related performance in elite athletes. Int. J. Sport Nutr. Exerc. Metab. 2011, 21, 97-104. [CrossRef] [PubMed]

128. Mero, A.A.; Huovinen, H.; Matintupa, O.; Hulmi, J.J.; Puurtinen, R.; Hohtari, H.; Karila, T.A. Moderate energy restriction with high protein diet results in healthier outcome in women. J. Int. Soc. Sports Nutr. 2010, 7, 4. [CrossRef] [PubMed]

129. Sandoval, W.M.; Heyward, V.H.; Lyons, T.M. Comparison of body composition, exercise and nutritional profiles of female and male body builders at competition. J. Sports Med. Phys. Fit. 1989, 29, 63-70.

130. Withers, R.T.; Noell, C.J.; Whittingham, N.O.; Chatterton, B.E.; Schultz, C.G.; Keeves, J.P. Body composition changes in elite male bodybuilders during preparation for competition. Aust. J. Sci. Med. Sport. 1997, 29, 11-16. [CrossRef]

131. van der Ploeg, G.E.; Brooks, A.G.; Withers, R.T.; Dollman, J.; Leaney, F.; Chatterton, B.E. Body composition changes in female bodybuilders during preparation for competition. Eur. J. Clin. Nutr. 2001, 55, 268-277. [CrossRef]

132. Forbes, G.B. Lean body mass-body fat interrelationships in humans. Nutr. Rev. 1987, 45, 225-231. [CrossRef]

133. Anderson, J. Obesity. Br. Med. J. 1972, 1, 560-563. [CrossRef]

134. Antoni, R.; Johnston, K.L.; Collins, A.L.; Robertson, M.D. Investigation into the acute effects of total and partial energy restriction on postprandial metabolism among overweight/obese participants. Br. J. Nutr. 2016, 115, 951-959. [CrossRef] [PubMed]

135. Bailey, B.W.; Jacobsen, D.J.; Donnelly, J.E. Weight loss and maintenance outcomes using moderate and severe caloric restriction in an outpatient setting. Dis. Manag. 2008, 11, 176-180. [CrossRef]

136. Christensen, P.; Bliddal, H.; Riecke, B.F.; Leeds, A.R.; Astrup, A.; Christensen, R. Comparison of a low-energy diet and a very low-energy diet in sedentary obese individuals: A pragmatic randomized controlled trial. Clin. Obes. 2011, 1, 31-40. [CrossRef] 
137. Helms, E.R.; Aragon, A.A.; Fitschen, P.J. Evidence-based recommendations for natural bodybuilding contest preparation: Nutrition and supplementation. J. Int. Soc. Sports Nutr. 2014, 11, 20. [CrossRef] [PubMed]

138. Gibson, A.A.; Seimon, R.V.; Franklin, J.; Markovic, T.P.; Byrne, N.M.; Manson, E.; Caterson, I.D.; Sainsbury, A. Fast versus slow weight loss: Development process and rationale behind the dietary interventions for the TEMPO Diet Trial. Obes. Sci. Pract. 2016, 2, 162-173. [CrossRef] [PubMed]

139. Byrne, N.M.; Weinsier, R.L.; Hunter, G.R.; Desmond, R.; Patterson, M.A.; Darnell, B.E.; Zuckerman, P.A. Influence of distribution of lean body mass on resting metabolic rate after weight loss and weight regain: Comparison of responses in white and black women. Am. J. Clin. Nutr. 2003, 77, 1368-1373. [CrossRef] [PubMed]

140. Byrne, N.M.; Hills, A.P. Biology or Behavior: Which Is the Strongest Contributor to Weight Gain? Curr. Obes. Rep. 2013, 2, 65-76. [CrossRef]

141. Elliot, D.L.; Goldberg, L.; Kuehl, K.S.; Bennett, W.M. Sustained depression of the resting metabolic rate after massive weight loss. Am. J. Clin. Nutr. 1989, 49, 93-96. [CrossRef] [PubMed]

142. Hulmi, J.J.; Isola, V.; Suonpaa, M.; Jarvinen, N.J.; Kokkonen, M.; Wennerstrom, A.; Nyman, K.; Perola, M.; Ahtiainen, J.P.; Hakkinen, K. The Effects of Intensive Weight Reduction on Body Composition and Serum Hormones in Female Fitness Competitors. Front. Physiol. 2016, 7, 689. [CrossRef] [PubMed]

143. Chappell, A.J.; Simper, T.; Barker, M.E. Nutritional strategies of high level natural bodybuilders during competition preparation. J. Int. Soc. Sports Nutr. 2018, 15, 4. [CrossRef] [PubMed]

144. Loucks, A.B.; Verdun, M. Slow restoration of LH pulsatility by refeeding in energetically disrupted women. Am. J. Physiol. 1998, 275, R1218-R1226. [CrossRef] [PubMed]

145. Olson, B.R.; Cartledge, T.; Sebring, N.; Defensor, R.; Nieman, L. Short-term fasting affects luteinizing hormone secretory dynamics but not reproductive function in normal-weight sedentary women. J. Clin. Endocrinol. Metab. 1995, 80, 1187-1193. [PubMed]

146. Hu, T.; Mills, K.T.; Yao, L.; Demanelis, K.; Eloustaz, M.; Yancy, W.S., Jr.; Kelly, T.N.; He, J.; Bazzano, L.A. Effects of low-carbohydrate diets versus low-fat diets on metabolic risk factors: A meta-analysis of randomized controlled clinical trials. Am. J. Epidemiol. 2012, 176 (Suppl. 7), S44-S54. [CrossRef] [PubMed]

147. Position of the American Dietetic Association, Dietitians of Canada, and the American College of Sports Medicine: Nutrition and athletic performance. J. Am. Diet. Assoc. 2000, 100, 1543-1556. [CrossRef]

148. Jequier, E. Leptin signaling, adiposity, and energy balance. Ann. N. Y. Acad. Sci. 2002, 967, 379-388. [CrossRef]

149. Jequier, E. Pathways to obesity. Int. J. Obes. Relat. Metab. Disord. 2002, 26 (Suppl. 2), S12-S17. [CrossRef]

150. Paddon-Jones, D.; Westman, E.; Mattes, R.D.; Wolfe, R.R.; Astrup, A.; Westerterp-Plantenga, M. Protein, weight management, and satiety. Am. J. Clin. Nutr. 2008, 87, 1558s-1561s. [CrossRef]

151. Pasiakos, S.M.; Cao, J.J.; Margolis, L.M.; Sauter, E.R.; Whigham, L.D.; McClung, J.P.; Rood, J.C.; Carbone, J.W.; Combs, G.F., Jr.; Young, A.J. Effects of high-protein diets on fat-free mass and muscle protein synthesis following weight loss: A randomized controlled trial. FASEB J. 2013, 27, 3837-3847. [CrossRef]

152. Weigle, D.S.; Breen, P.A.; Matthys, C.C.; Callahan, H.S.; Meeuws, K.E.; Burden, V.R.; Purnell, J.Q. A high-protein diet induces sustained reductions in appetite, ad libitum caloric intake, and body weight despite compensatory changes in diurnal plasma leptin and ghrelin concentrations. Am. J. Clin. Nutr. 2005, 82, 41-48. [CrossRef]

153. Phillips, S.M. Dietary protein for athletes: From requirements to metabolic advantage. Appl. Physiol. Nutr. Metab. 2006, 31, 647-654. [CrossRef]

154. Phillips, S.M.; Van Loon, L.J. Dietary protein for athletes: From requirements to optimum adaptation. J. Sports Sci. 2011, 29 (Suppl. S1), S29-S38. [CrossRef] [PubMed]

155. Lemon, P.W. Beyond the zone: Protein needs of active individuals. J. Am. Coll. Nutr. 2000, 19, 513s-521s. [CrossRef]

156. Tipton, K.D.; Wolfe, R.R. Protein and amino acids for athletes. J. Sports Sci. 2004, 22, 65-79. [CrossRef] [PubMed]

157. Ludwig, D.S. Lowering the Bar on the Low-Fat Diet. JAMA 2016, 316, 2087-2088. [CrossRef] [PubMed]

158. Boaz, M.; Raz, O. Low Fat vs. Low Carbohydrate Diet Strategies for Weight Reduction: A Meta-Analysis. J. Obes. Weight Loss Ther. 2015, 5. [CrossRef]

159. Hall, K.D. A review of the carbohydrate-insulin model of obesity. Eur. J. Clin. Nutr. 2017, 71, $323-326$. [CrossRef] 
160. Thomas, D.T.; Erdman, K.A.; Burke, L.M. Position of the Academy of Nutrition and Dietetics, Dietitians of Canada, and the American College of Sports Medicine: Nutrition and Athletic Performance. J. Acad. Nutr. Diet. 2016, 116, 501-528. [CrossRef]

161. Cole, M.; Coleman, D.; Hopker, J.; Wiles, J. Improved gross efficiency during long duration submaximal cycling following a short-term high carbohydrate diet. Int. J. Sports Med. 2014, 35, 265-269. [CrossRef]

162. Spriet, L.L. New insights into the interaction of carbohydrate and fat metabolism during exercise. Sports Med. 2014, 44 (Suppl. 1), S87-S96. [CrossRef]

163. Leveritt, M.; Abernethy, P.J.; Barry, B.K.; Logan, P.A. Concurrent strength and endurance training. A review. Sports Med. 1999, 28, 413-427. [CrossRef] [PubMed]

164. Burke, L.M.; Ross, M.L.; Garvican-Lewis, L.A.; Welvaert, M.; Heikura, I.A.; Forbes, S.G.; Mirtschin, J.G.; Cato, L.E.; Strobel, N.; Sharma, A.P.; et al. Low carbohydrate, high fat diet impairs exercise economy and negates the performance benefit from intensified training in elite race walkers. J. Physiol. 2017, 595, 2785-2807. [CrossRef] [PubMed]

165. Burke, L.M.; Hawley, J.A.; Wong, S.H.; Jeukendrup, A.E. Carbohydrates for training and competition. J. Sports Sci. 2011, 29 (Suppl. 1), S17-S27. [CrossRef]

166. Haff, G.G.; Lehmkuhl, M.J.; McCoy, L.B.; Stone, M.H. Carbohydrate supplementation and resistance training. J. Strength Cond. Res. 2003, 17, 187-196. [PubMed]

167. Escobar, K.A.; Morales, J.; Vandusseldorp, T.A. The Effect of a Moderately Low and High Carbohydrate Intake on Crossfit Performance. Int. J. Exerc. Sci. 2016, 9, 460-470.

168. Jenkins, A.B.; Markovic, T.P.; Fleury, A.; Campbell, L.V. Carbohydrate intake and short-term regulation of leptin in humans. Diabetologia 1997, 40, 348-351. [CrossRef]

169. Wang, L.; Rhodes, C.J.; Lawrence, J.C., Jr. Activation of mammalian target of rapamycin (mTOR) by insulin is associated with stimulation of 4EBP1 binding to dimeric mTOR complex 1. J. Biol. Chem. 2006, 281, 24293-24303. [CrossRef] [PubMed]

170. Bird, S.P.; Tarpenning, K.M.; Marino, F.E. Independent and combined effects of liquid carbohydrate/essential amino acid ingestion on hormonal and muscular adaptations following resistance training in untrained men. Eur. J. Appl. Physiol. 2006, 97, 225-238. [CrossRef] [PubMed]

171. Kelley, D.E.; Goodpaster, B.; Wing, R.R.; Simoneau, J.A. Skeletal muscle fatty acid metabolism in association with insulin resistance, obesity, and weight loss. Am. J. Physiol. 1999, 277, E1130-E1141. [CrossRef]

172. Kelley, D.E.; Goodpaster, B.H.; Storlien, L. Muscle triglyceride and insulin resistance. Annu. Rev. Nutr. 2002, 22, 325-346. [CrossRef]

173. Astrup, A.; Buemann, B.; Christensen, N.J.; Madsen, J. 24-hour energy expenditure and sympathetic activity in postobese women consuming a high-carbohydrate diet. Am. J. Physiol. 1992, 262, E282-E288. [CrossRef] [PubMed]

174. Ballor, D.L.; Harvey-Berino, J.R.; Ades, P.A.; Cryan, J.; Calles-Escandon, J. Decrease in fat oxidation following a meal in weight-reduced individuals: A possible mechanism for weight recidivism. Metab. Clin. Exp. 1996, 45, 174-178. [CrossRef]

175. Bessesen, D.H.; Rupp, C.L.; Eckel, R.H. Dietary fat is shunted away from oxidation, toward storage in obese Zucker rats. Obes. Res. 1995, 3, 179-189. [CrossRef] [PubMed]

176. Steig, A.J.; Jackman, M.R.; Giles, E.D.; Higgins, J.A.; Johnson, G.C.; Mahan, C.; Melanson, E.L.; Wyatt, H.R.; Eckel, R.H.; Hill, J.O.; et al. Exercise reduces appetite and traffics excess nutrients away from energetically efficient pathways of lipid deposition during the early stages of weight regain. Am. J. Physiol. Regul. Integr. Comp. Physiol. 2011, 301, R656-R667. [CrossRef] [PubMed]

177. Schutz, Y. Dietary fat, lipogenesis and energy balance. Physiol. Behav. 2004, 83, 557-564. [CrossRef]

178. Dorgan, J.F.; Judd, J.T.; Longcope, C.; Brown, C.; Schatzkin, A.; Clevidence, B.A.; Campbell, W.S.; Nair, P.P.; Franz, C.; Kahle, L.; et al. Effects of dietary fat and fiber on plasma and urine androgens and estrogens in men: A controlled feeding study. Am. J. Clin. Nutr. 1996, 64, 850-855. [CrossRef] [PubMed] 
179. Burke, L.M. Re-Examining High-Fat Diets for Sports Performance: Did We Call the 'Nail in the Coffin' Too Soon? Sports Med. 2015, 45 (Suppl. 1), S33-S49. [CrossRef]

180. Walberg, J.L.; Leidy, M.K.; Sturgill, D.J.; Hinkle, D.E.; Ritchey, S.J.; Sebolt, D.R. Macronutrient content of a hypoenergy diet affects nitrogen retention and muscle function in weight lifters. Int. J. Sports Med. 1988, 9, 261-266. [CrossRef] 